\title{
ACTUALIZACIÓN SISTEMÁTICA Y FILOGENIA DE LOS PROTEROTHERIIDAE (MAMMALIA, LITOPTERNA) DEL "MESOPOTAMIENSE" (MIOCENO TARDÍO) DE ENTRE RÍOS, ARGENTINA
}

\author{
GABRIELA INÉS SCHMIDT \\ Laboratorio de Paleontología de Vertebrados, Centro de Investigaciones Científicas y Transferencia de Tecnología \\ a la Producción (CICYTTP-CONICET), Materi y España (E3105BWA), Diamante, Entre Ríos, Argentina. \\ gschmidt@cicyttp.org.ar
}

\begin{abstract}
SYSTEMATIC UPDATE AND PHYLOGENY OF THE PROTEROTHERIIDAE (MAMMALIA, LITOPTERNA) FROM THE "MESOPOTAMIENSE" (LATE MIOCENE) OF ENTRE RÍOS PROVINCE, ARGENTINA. A systematic update of the species of Proterotheriidae (Litopterna) from the "Mesopotamiense" of Entre Ríos Province (Argentina) is performed, and their phylogenetic relationships with other members of the family are tested. Brachytherium cuspidatum Ameghino is validated (considered nomen dubium hitherto) and a sexual dimorphism is proposed for this species. This idea is based on metric, but not morphological, differences among the specimens included in it, which is supported by a discriminant analysis. Neobrachytherium ameghinoi Soria and Proterotherium cervioides Ameghino are also valid, and Epitherium? eversus (Ameghino) is assigned to the genus Diadiaphorus. Detailed descriptions of the specimens are presented for each taxon, and their diagnosis are revised.
\end{abstract}

Key words: Proterotheriidae, Ituzaingó Formation, Entre Ríos Province, systematics, phylogeny.

RESUMO - Uma atualização sistemática, das espécies de Proterotheriidae (Litopterna) presentes no "Mesopotamiense" da Província de Entre Ríos, Argentina, é realizada, bem como são testadas as suas relações filogenéticas com outros integrantes da família. Brachytherium cuspidatum (previamente considerada nomen dubium) é revalidada, e um dimorfismo sexual é proposto para esta espécie. Esta ideia se fundamenta nas diferenças métricas e não morfológicas, que apresentam os seus exemplares, a qual está suportada por uma análise descriminante. Neobrachytherium ameghinoi Soria e Proterotherium cervioides Ameghino são também validados, e Epitherium? eversus (Ameghino) é assignado ao gênero Diadiaphorus. Uma descrição detalhada dos espécimes é efetuada para cada táxon, sendo as diagnoses também revisadas.

Palavras-chave: Proterotheriidae, Formação Ituzaingó, Entre Ríos, sistemática, filogenia.

\section{INTRODUCCIÓN}

El orden Litopterna forma parte de un grupo de mamíferos conocido como ungulados nativos sudamericanos (Bond et al., 1995; Villafañe et al., 2006; Vucetich et al., 2007; Welker et al., 2015). Dentro de este orden, cuyo biocrón se extiende desde el Paleoceno tardío al Pleistoceno tardío, se reconocen varias familias: Protolipternidae, Notonychopidae, Adianthidae, Proterotheriidae y Macraucheniidae (Gervais, 1855; Ameghino, 1887b, 1891; Cifelli, 1983a; Soria, 1989; Scherer et al., 2009; Buckley, 2015). Los Sparnotheriodontidae fueron clasificados como "Condylarthra" (Cifelli, 1983a,b; Mones, 1986; Bergqvist, 2008), aunque otros autores los consideraron parte de los Litopterna (Soria, 2001; Bond et al., 2006).

Los Proterotheriidae eran animales cursoriales, herbívoros, de tamaño pequeño a mediano, con dentición braquiodonte, mesodonte o, incluso, protohipsodonte (Villafañe et al., 2006, 2012). Ocuparon varios ambientes, desde zonas forestadas hasta sitios más abiertos (Bond et al., 2001; Villafañe et al., 2006; Ubilla et al., 2011). Se caracterizaron por la reducción de los dígitos laterales II y IV y por haber adquirido una monodactilia funcional similar a la de los équidos Anchitheriinae extintos o incluso más extrema que en los équidos vivientes (Ubilla et al., 2011). El género Thoatherium Ameghino, 1887b, llegó a perder los dedos laterales, logrando una monodactilia estructural (Kraglievich, 1930; Soria, 2001; Cassini et al., 2012). Este grupo alcanzó su máxima diversidad taxonómica durante el Mioceno temprano (edad Santacrucense) y el Mioceno tardío (edad Huayqueriense) (Villafañe et al., 2006; Ubilla et al., 2011).

De las tres subfamilias reconocidas dentro de los Proterotheriidae, Anisolambdinae, Megadolodinae y Proterotheriinae (Villafañe et al., 2006, 2012), sólo la última está registrada en la fauna "mesopotamiense", procedente de los niveles basales de la Formación Ituzaingó en la Provincia de Entre Ríos. Este nivel constituye el registro más importante de Proterotheriidae para el Mioceno tardío de Argentina, al tiempo que durante el lapso Oligoceno-Mioceno medio los principales representantes se circunscriben a la región patagónica (Soria, 2001, p.149). 
Varios autores realizaron importantes aportes a la sistemática de los proterotéridos de Entre Ríos (Burmeister, 1891; Kraglievich, 1931; Pascual \& Odreman Rivas, 1971; Soria, 2001 y referencias incluidas allí), aunque Delupi de Bianchini \& Bianchini (1971) se ocuparon de ellos de manera particular. El propósito de este trabajo es actualizar el conocimiento sistemático de los proterotéridos del "Mesopotamiense" de Entre Ríos, ampliar las diagnosis de los taxones reconocidos y analizar sus relaciones filogenéticas con otros representantes de la familia a partir de los análisis previos.

\section{CONTEXTO GEOGRÁFICO, ESTRATIGRÁFICO Y EDAD}

Diversos autores han realizado notables aportes respecto al conocimiento estratigráfico y paleontológico del "Mesopotamiense" (e.g. Bravard, 1858; Ameghino, 1883a, 1885, 1889; Frenguelli, 1920, Aceñolaza, 1976; Cione et al., 2000). El "Mesopotamiense" (sensu Frenguelli, 1920), "conglomerado osífero" o miembro inferior de la Formación Ituzaingó (sensu Brunetto et al., 2013) aflora sobre la margen izquierda del río Paraná en la Provincia de Entre Ríos, desde la localidad de Hernandarias, al norte, hasta la ciudad de Paraná, al sur, y en sus principales arroyos tributarios (Brandoni, 2011). Las localidades Curtiembre, Arroyo El Chapetón, Bajada La Celina, Villa Urquiza y Toma Vieja se encuentran entre las más prospectadas y han aportado la mayoría de los especímenes colectados (Figura 1).

El "Mesopotamiense" es un nivel areno-arcilloso y conglomerádico asociado a la discordancia erosiva que lo separa de la Formación Paraná infrayacente. Se ubica en la base de la Formación Ituzaingó y presenta afloramientos saltuarios a lo largo de la margen izquierda del río Paraná. Los fósiles provenientes de este nivel, a menudo fragmentados y disociados, pertenecen en su mayoría a vertebrados continentales y marinos (Brandoni, 2005, 2011). Los restos están cementados por una arcilla arenosa impregnada de óxidos de hierro y manganeso, que le otorgan un color amarillento a ocráceo; son pesados, duros, presentan infiltraciones silíceas y ferruginosas y están manchados por óxido de manganeso (Brandoni, 2011; Schmidt, 2013).

La edad del "Mesopotamiense" ha tenido diferentes interpretaciones (Pascual, 1970; Pascual \& Odreman Rivas, 1971). Cione et al. (2000), a partir de las relaciones biocronológicas existentes con otros niveles fosilíferos, concluyeron que la fauna correspondería a la edad Huayqueriense, correlacionable con el Tortoniano de la escala cronoestratigráfica internacional (11,6-7,2 Ma). Sin embargo, los nuevos análisis paleobiogeográficos y las correlaciones cronológicas de los vertebrados del "Mesopotamiense" indican la posibilidad de que dicha fauna comenzara a establecerse en tiempos previos al Huayqueriense (Brandoni, 2009, 2011, 2013; Candela et al., 2012; Schmidt, 2013).

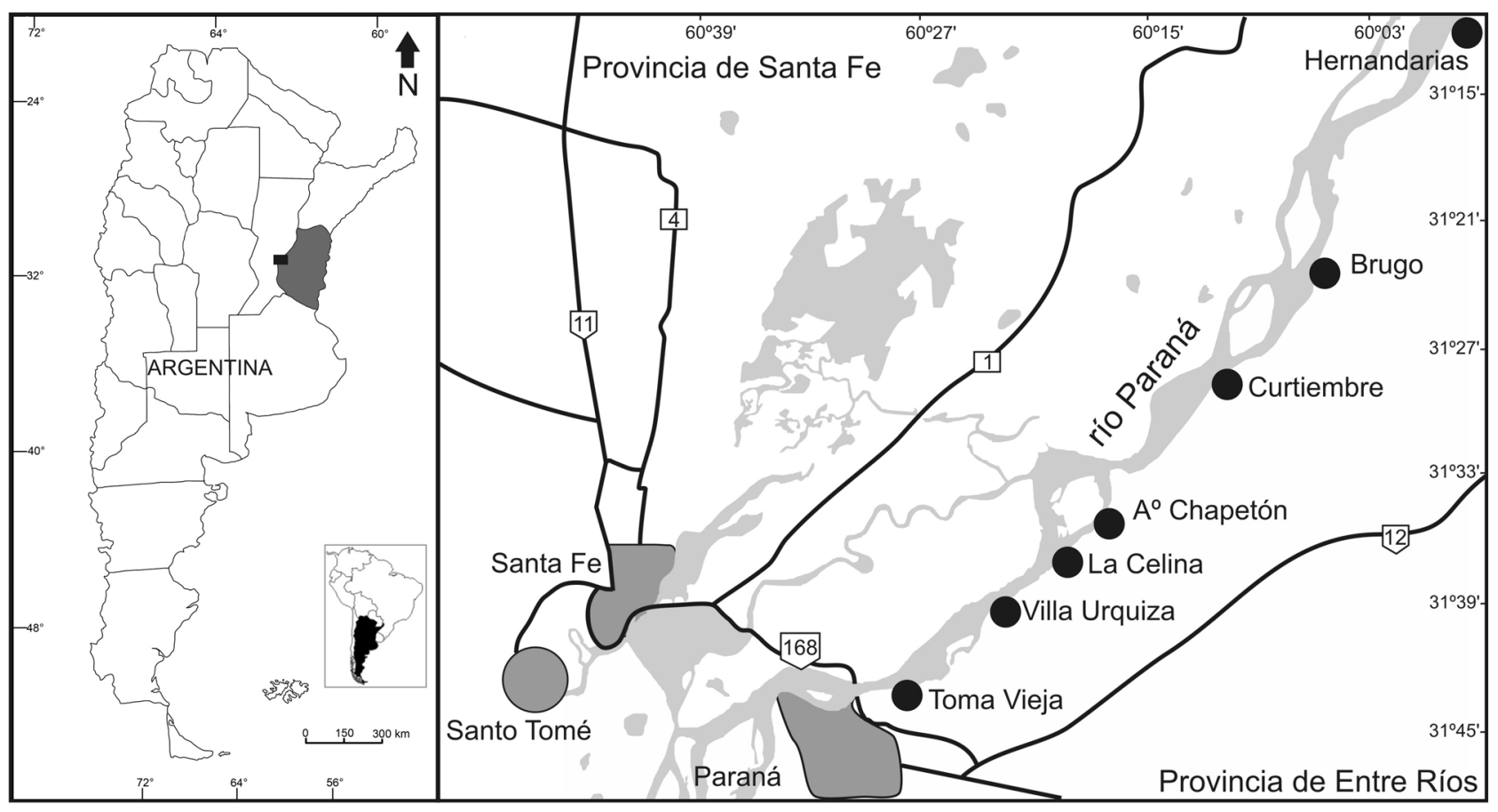

Figura 1. Ubicación geográfica de las localidades donde aflora el "Mesopotamiense" en la Provincia de Entre Ríos (modificado de Brunetto et al., 2013; Góis et al., 2013).

Figure 1. Geographic location of the localities where the "Mesopotamian" outcrops in Entre Ríos Province (modified from Brunetto et al., 2013; Góis et al., 2013). 


\section{MATERIAL Y MÉTODOS}

El material estudiado consiste en piezas dentarias. Cada resto fue descripto, fotografiado y medido con un calibre, registrándose sus medidas en milímetros (Apéndice 1, Tablas 1-2).

Para la descripción, se siguieron fundamentalmente los trabajos de Delupi de Bianchini \& Bianchini (1971), Soria (2001), Kramarz \& Bond (2005) y Villafañe et al. (2012) (Figura 2). Se efectuó un estudio comparado - morfológico y métrico - estableciendo semejanzas y diferencias entre los ejemplares y con taxones mio-pliocenos de otras regiones geográficas.

Los análisis discriminantes se realizaron con el programa InfoStat 1.1. Esta técnica estadística segrega, en base a las variables métricas seleccionadas, grupos definidos a priori y representa las observaciones en un espacio donde las diferencias entre grupos sean máximas (InfoStat, 2002). Las variables métricas seleccionadas fueron la longitud y la anchura de p3-m3. Se confeccionaron cuatro gráficos considerando las variables

Tabla 1. Medidas $(\mathrm{mm})$ de la dentición superior de los ejemplares de los taxones mencionados en el texto. Abreviaturas: A, ancho; DP, Premolar deciduo; L, largo; $\mathbf{M}$, molar; $\mathbf{P}$, premolar.

Table 1. Measurements $(\mathrm{mm})$ of the upper dentition of specimens of taxa mentioned in the text. Abbreviations: A, width; DP, deciduous premolar; $\mathbf{L}$, length; $\mathbf{M}$, molar; $\mathbf{P}$, premolar.

\begin{tabular}{|c|c|c|c|c|c|c|c|c|c|c|}
\hline & DP1 & DP2 & DP3 & DP4 & $\mathrm{P} 2$ & P3 & $\mathrm{P} 4$ & M1 & M2 & M3 \\
\hline & $\mathrm{L} / \mathrm{A}$ & $\mathrm{L} / \mathrm{A}$ & $\mathrm{L} / \mathrm{A}$ & $\mathrm{L} / \mathrm{A}$ & $\mathrm{L} / \mathrm{A}$ & $\mathrm{L} / \mathrm{A}$ & $\mathrm{L} / \mathrm{A}$ & $\mathrm{L} / \mathrm{A}$ & $\mathrm{L} / \mathrm{A}$ & $\mathrm{L} / \mathrm{A}$ \\
\hline \multicolumn{11}{|c|}{ Brachytherium cuspidatum } \\
\hline MLP 81-XI-29-8 & $8,1 / 6,5$ & $8,3 / 7,7$ & $10,1 / 9,4$ & $10,5 / 10,8$ & & & & & & \\
\hline MACN A 11000a & & & & $14,5 / 15,9$ & & & & & & \\
\hline MACN A-5865 & & & & & $13,3 / 11,8$ & $13,6 / 14,7$ & & & & \\
\hline MLP 69-XII-2-11 & & & & & & $14,0 / ?$ & $14,1 / 17,5$ & $14,3 / 19,0$ & & \\
\hline FCP-V-M-053 & & & & & & & $14,9 / 16,5$ & $16,2 / 18,1$ & $16,8 / 18,2$ & \\
\hline MACN PV 16009 & & & & & & & & $14,9 / 17,4$ & & \\
\hline MACN A-5864 & & & & & & & & $13,6 / 16,8$ & & \\
\hline MACN PV 13189 & & & & & & & & $13,2 / 15,7$ & & \\
\hline MACN PV 16009a & & & & & & & & & $16,7 / 21,2$ & $11,9 / 17,2$ \\
\hline MACN PV 16009b & & & & & & & & & $16,1 / 19,7$ & $13,2 / 19,8$ \\
\hline MACN PV 14303 & & & & & & & & & $16,6 / 19,1$ & $12,8 / 16,8$ \\
\hline MACN PV 9250 & & & & & & & & & & $12,6 / 18,1$ \\
\hline \multicolumn{11}{|c|}{ Neobrachytherium ameghinoi } \\
\hline MACN PV 9150 & & & & & & & & $14,1 / 16,3$ & & \\
\hline MACN PV 13212 & & & & & & & & $14,6 / 19,8$ & & \\
\hline MLP M-177 & & & & & & & & $14,1 / 18,5$ & & \\
\hline MLP M-178 & & & & & & & & & & $14,6 / 20,4$ \\
\hline \multicolumn{11}{|c|}{ Neobrachytherium morenoi } \\
\hline MACN PV 8428 der. & & & & & & & & $13,2 / 15,4$ & $15,1 / 18,1$ & \\
\hline MACN PV 8428 izq. & & & & & & & $12,9 / 14,0$ & $13,6 / 16,1$ & $14,8 / 17,2$ & \\
\hline MACN PV 8435 & & & & & & & $13,1 / ?$ & & & \\
\hline \multicolumn{11}{|c|}{ Neobrachytherium ullumense } \\
\hline PVSJ 120 der. & & & & & & & $11,6 / 15$ & $13,0 / 16,4$ & $(13,4) / 17,3$ & $13,8 / 16,6$ \\
\hline PVSJ 120 izq. & & & & & & & $12,4 / 15$ & $11,4 / 15,5$ & $14,7 / 18$ & $? / ?$ \\
\hline MCNAM PV 3222 & & & & & & & $12,3 / ?$ & $13,0 / 15,5$ & $14,5 / 18$ & $13,3 / 17,8$ \\
\hline \multicolumn{11}{|c|}{ Neobrachytherium sp. (La Rioja) } \\
\hline CRILAR PV 429 der. & & & & & & $11,1 / 13,4$ & $12,0 / 15,0$ & $13,6 / 16,6$ & & \\
\hline CRILAR PV 429 izq. & & & & & & $11,2 / 12,4$ & & & & \\
\hline \multicolumn{11}{|c|}{ Proterotherium cervioides } \\
\hline MLP 69-XII-2-9 & & & & & & & $8,1 / 10,2$ & $9,4 / 10,9$ & $9,9 / 12,9$ & \\
\hline \multicolumn{11}{|l|}{ Diadiaphorus eversus } \\
\hline MACN A-5866 & & & & & & & & $15,25 / ?$ & & \\
\hline
\end{tabular}


Tabla 2. Medidas $(\mathrm{mm})$ de la dentición inferior de los ejemplares de los taxones mencionados en el texto. Abreviaturas: A, ancho; dp, premolar deciduo; L, largo; $\mathbf{m}$, molar; $\mathbf{p}$, premolar.

Table 2. Measurements $(\mathrm{mm})$ of the lower dentition of specimens of taxa mentioned in the text. Abbreviations: A, width; dp, deciduous premolar; $\mathbf{L}$, length; $\mathbf{m}$, molar; $\mathbf{p}$, premolar.

\begin{tabular}{|c|c|c|c|c|c|c|c|c|c|c|}
\hline & $\mathrm{dp} 2$ & dp3 & $\mathrm{dp} 4$ & $\mathrm{p} 1$ & $\mathrm{p} 2$ & p3 & $\mathrm{p} 4$ & $\mathrm{~m} 1$ & $\mathrm{~m} 2$ & $\mathrm{~m} 3$ \\
\hline & $\mathrm{L} / \mathrm{A}$ & $\mathrm{L} / \mathrm{A}$ & $\mathrm{L} / \mathrm{A}$ & $\mathrm{L} / \mathrm{A}$ & $\mathrm{L} / \mathrm{A}$ & $\mathrm{L} / \mathrm{A}$ & $\mathrm{L} / \mathrm{A}$ & $\mathrm{L} / \mathrm{A}$ & $\mathrm{L} / \mathrm{A}$ & $\mathrm{L} / \mathrm{A}$ \\
\hline \multicolumn{11}{|l|}{ Brachytherium cuspidatum } \\
\hline MLP 69-XII-2-4 & $14,6 / 6,7$ & $17,1 / 9,8$ & $14,4 / 9,8$ & & & & & $13,4 / 9,5$ & & \\
\hline MLP 12-110a & & $19,3 / 10,2$ & $16 / 10,5$ & & & & & $15,9 / 11,4$ & & \\
\hline MACN PV 1208 & & & $16,15 / 10,6$ & & & & & & & \\
\hline MACN PV 13172 & & & $14,5 / 9,7$ & & & & & & & \\
\hline MACN PV 9155 & & & $15,5 / 10,9$ & & & & & & & \\
\hline MACN PV 9156 & & & $13,2 / 10,1$ & & & & & & & \\
\hline MAS PALEO-VERT 400 & & & $15,2 / 10,1$ & & & & & & & \\
\hline MAS PALEO-VERT 401 & & & $14,6 / 10,1$ & & & & & & & \\
\hline MACN PV 4677 & & & & $12,8 / 4,1$ & $16,5 / 6,1$ & $17,6 / 11,4$ & $16,8 / 12,8$ & & & \\
\hline MACN PV 3962 & & & & & $? / 7,29$ & $15,1 / 11,9$ & $14,6 / 14,1$ & $12,9 / 12,9$ & $14,8 / 12,9$ & $17,3 / 10,8$ \\
\hline MLP 12-1483 & & & & & $16,9 / 8,1$ & $17,8 / 12,8$ & $15,7 / 15,6$ & $14,9 / 14,1$ & $16,2 / 14,2$ & $16,7 / 12,7$ \\
\hline MLP $12-103$ a & & & & & & $14,6 / 10,7$ & $12,8 / 10,9$ & $11,9 / 11,0$ & & \\
\hline MLP 81-XI-29-2 & & & & & & $17,1 / 11,2$ & & & & \\
\hline MACN PV 4747 & & & & & & $16,5 / 11,4$ & & & & \\
\hline MACN PV 9249 & & & & & & & $15,2 / 12,1$ & & & \\
\hline MACN PV 14305 & & & & & & $15,1 / 11,1$ & $14,4 / 12,6$ & & & \\
\hline MACN PV 13187 & & & & & & $13,9 / 10,6$ & $13,3 / 11,8$ & & & \\
\hline MACN PV 4058 & & & & & & $18,1 / 11,8$ & $15,5 / 14,1$ & $15,3 / 12,5$ & & \\
\hline MACN PV 4717 & & & & & & $16,5 / 11,1$ & $14,5 / 12,5$ & $14,1 / 11,6$ & $14,8 / 11,1$ & \\
\hline MLP 41-XII-13-348 & & & & & & $16,2 / 10,6$ & $14,9 / 12,1$ & $15,1 / 10,8$ & & \\
\hline MACN PV 14306 & & & & & & $15,3 / 10,3$ & $13,9 / 11,1$ & $13,1 / 12,4$ & & \\
\hline MLP 69-XII-2-3 & & & & & & $16,8 / 11,7$ & $15,9 / 13,1$ & $14,4 / 12,7$ & $16,4 / 11,7$ & \\
\hline MACN PV 13173 & & & & & & $11,9 / 8,2$ & $12,1 / 9,0$ & $12,2 / 9,9$ & $14 / 10,1$ & \\
\hline MLP 70-I-10-3 & & & & & & $14,5 / 11,1$ & $13,2 / 12,3$ & $13,1 / 11,9$ & $13,7 / 11,9$ & $15,3 / 11,7$ \\
\hline MAS PALEO-VERT 402 & & & & & & $15,6 / 10,7$ & $13,3 / 11,2$ & $12,5 / 10,9$ & $14,4 / 12,0$ & $15,2 / 10,0$ \\
\hline MACN PV 4433 & & & & & & & & $13,4 / 10,9$ & & \\
\hline MACN PV 3177 & & & & & & & $14,7 / 12,6$ & $14,8 / 10,7$ & & \\
\hline MACN PV 13171 & & & & & & & $15,8 / 12,9$ & $14 / 11,2$ & $16,5 / 12,5$ & \\
\hline MLP 52-X-1-72 & & & & & & & $15,9 / 13,2$ & $14,7 / 12,5$ & $14,7 / 11,4$ & $17,6 / 11,1$ \\
\hline MACN PV 4435 & & & & & & & $13,2 / 11,0$ & $12,2 / 11,1$ & $13,3 / 11,1$ & $13,7 / 9,6 ?$ \\
\hline MACN PV 4001 & & & & & & & $12,4 / 10,1$ & $11,4 / 10,3$ & $12,9 / 10,1$ & $14,7 / 9,1$ \\
\hline MACN PV 9141 & & & & & & & & $14,0 / 12,1$ & $14,5 / 12,0$ & $15,9 / 10,4$ \\
\hline MACN PV 4404 & & & & & & & & $14,4 / 11,5$ & $16,4 / 12,5$ & \\
\hline MACN PV 4750 & & & & & & & & & $16,1 / 12,5$ & $19,2 / 12,1$ \\
\hline MACN PV 4121 & & & & & & & & & $16,6 / 16,1$ & $18,6 / 13,1$ \\
\hline MLP 41-XII-13-345 & & & & & & & & & $15,5 / 11,3$ & $15,7 / 10,5$ \\
\hline MACN PV 4009 & & & & & & & & & $14,7 / 12$ & $15,9 / 10,6$ \\
\hline MACN PV 16009 & & & & & & & & & $16,2 / 11,9$ & \\
\hline MLP 69-XII-2-6 & & & & & & & & & $16,2 / 12,9$ & \\
\hline CICYTTP-PV-M-1-925 & & & & & & & & & $14,8 / 11$ & \\
\hline MACN PV 14302 & & & & & & & & & & $17,8 / 10,7$ \\
\hline \multicolumn{11}{|l|}{ Neobrachytherium ameghinoi } \\
\hline MACN PV 14308 & & & & & & & $14,3 / 12,2$ & $12,9 / 10,9$ & $13,7 / 10,8$ & $16,2 / 10,3$ \\
\hline MLP 12-102a & & & & & & & $14,6 / 11,3$ & $13,5 / 9,5$ & $15,2 / 10,0$ & $14,5 / 9,5$ \\
\hline MACN PV 4748 & & & & & & & & $14,4 / 12,4$ & $15,0 / 13,0$ & $15,9 / 11,4$ \\
\hline
\end{tabular}


Tabla 2. Continuación.

Table 2. Continuation.

\begin{tabular}{|c|c|c|c|c|c|c|c|c|c|c|}
\hline & $\mathrm{dp} 2$ & dp3 & dp4 & p1 & $\mathrm{p} 2$ & p3 & $\mathrm{p} 4$ & $\mathrm{~m} 1$ & $\mathrm{~m} 2$ & $\mathrm{~m} 3$ \\
\hline & $\mathrm{L} / \mathrm{A}$ & $\mathrm{L} / \mathrm{A}$ & $\mathrm{L} / \mathrm{A}$ & $\mathrm{L} / \mathrm{A}$ & $\mathrm{L} / \mathrm{A}$ & $\mathrm{L} / \mathrm{A}$ & $\mathrm{L} / \mathrm{A}$ & $\mathrm{L} / \mathrm{A}$ & $\mathrm{L} / \mathrm{A}$ & $\mathrm{L} / \mathrm{A}$ \\
\hline MLP 69-XII-2-5 & & & & & & & & $13,1 / 11,9$ & $14,8 / 11,3$ & \\
\hline MLP 37-III-10-2 & & & & & & & & & $16,7 / 12,7$ & $17,1 / 11,0$ \\
\hline MACN PV 3999 & & & & & & & & & $14,5 / 11,6$ & \\
\hline MACN PV 2619 & & & & & & & & & & $17,2 / 11,1$ \\
\hline MACN PV 3998 & & & & & & & & & & $16,2 / 10,4$ \\
\hline MACN PV 13164 & & & & & & & & & & $16,5 / 9,5$ \\
\hline \multicolumn{11}{|c|}{ Neobrachytherium morenoi } \\
\hline MACN PV 8431 & & & & & $11,4 / 5,4$ & $12,9 / 9,1$ & $12,3 / 11,2$ & $? / ?$ & & \\
\hline PVL 3196 & & & $13,8 ? / 9,8$ & & & & & $12,7 / 9,9$ & & \\
\hline \multicolumn{11}{|c|}{ Neobrachytherium ullumense } \\
\hline PVSJ 135 & & & & & & & & & & $15,5 / 9,5$ \\
\hline MCNAM PV 3223 & & & & & & & & & $14,2 / 11,9$ & $15,4 / 10,9$ \\
\hline \multicolumn{11}{|c|}{ Proterotherium cervioides } \\
\hline MACN PV 2631 & & & $10,2 / 7,1$ & & & & & & & \\
\hline
\end{tabular}

de a pares: p3-p4, p4-m1, m1-m2 y m2-m3 (Apéndice 2). Estos gráficos muestran las diferencias existentes entre los grupos en función de los valores que toman dichas variables. Finalmente, se realizó un análisis filogenético mediante el uso del programa TNT (Tree analysis using New Technology) (Goloboff et al., 2008) para testear la posición de los taxones "Mesopotamienses". Se tomó como referencia la matriz de Villafañe et al. (2012) y las modificaciones realizadas se detallan en el apartado correspondiente.

Abreviaturas institucionales. CICYTTP-PV-M, Centro de Investigaciones científicas y Transferencia de Tecnología a la Producción, Diamante, Argentina, Paleovertebrados, Mamíferos; CRILAR Pv, Departamento de Geociencias, Centro Regional de Investigaciones Científicas y Transferencia Tecnológica, Anillaco, La Rioja, Argentina; FCP-V-M, Fundación Casa del Pueblo, Museo de Paleontología, Mineralogía y Arqueología, Firmat, Santa Fe, Argentina; FMNH, Field Museum of Natural History, Chicago, USA; MACN-A, Colección Nacional Ameghino, Museo Argentino de Ciencias Naturales "Bernardino Rivadavia", Buenos Aires, Argentina; MACN, Museo Argentino de Ciencias Naturales "Bernardino Rivadavia", Buenos Aires, Argentina (A, Colección Ameghino; PV, Colección de Paleovertebrados); MAS PALEO-VERT, Colección de Paleontología de Vertebrados, Museo de Ciencias Naturales y Antropológicas "Profesor Antonio Serrano", Paraná, Entre Ríos, Argentina; MCNAM-PV, Museo de Ciencias Naturales y Antropológicas “J. C. Moyano", Colección de Paleontología de Vertebrados, Mendoza, Argentina; MLP, Museo de La Plata. Facultad de Ciencias Naturales y Museo, La Plata, Buenos Aires, Argentina; MPCN, Museo Paleontológico y de Ciencias
Naturales "Alejandro C. Berro", Mercedes, Uruguay; PVL, Fundación Miguel Lillo (colección Paleontología de Vertebrados), San Miguel de Tucumán, Argentina; PVSJ, Museo de la Universidad de San Juan, Argentina.

Abreviaturas anatómicas y métricas. A, ancho; Ci.al, cíngulo anterolingual; clb, cíngulo labial; cli, cíngulo lingual; c.o, crístida obliqua; DP/dp, premolar superior/inferior deciduo; ecx, ectofléxido; end, entocónido; enx, entofléxido; Fo.c, foseta central; Fo.p, foseta posterior; Hi, hipocono; hicd, hipoconúlido; hid, hipocónido; hld, hipolófido; L, largo; M/m, molar superior/inferior; Me, metacono; Mec, metacónulo; med, metacónido; Met, metastilo; mex, metafléxido; mld, metalófido; Mst, mesostilo; P/p, premolar superior/inferior; Pa, paracono; Pac, paracónulo; pad, paracónido; Pat, parastilo; pld, paralófido; PI. me, pliegue del metacono; Pl. pa, pliegue del paracono; Po.c, postcíngulum; Pr, protocono; prd, protocónido; Su.ap, surco anteroposterior; Su.po, surco posterior.

\section{PALEONTOLOGÍA SISTEMÁTICA}

Orden LITOPTERNA Ameghino, 1889

Suborden LOPHOLIPTERNA Cifelli, 1983a

Familia PROTEROTHERIIDAE Ameghino, 1887b

Brachytherium Ameghino, 1883b

Especie tipo. Brachytherium cuspidatum Ameghino, 1883b.

Distribución geográfica y estratigráfica. Barrancas del río Paraná, Entre Ríos. "Mesopotamiense", base de la Formación Ituzaingó (Mioceno tardío). 

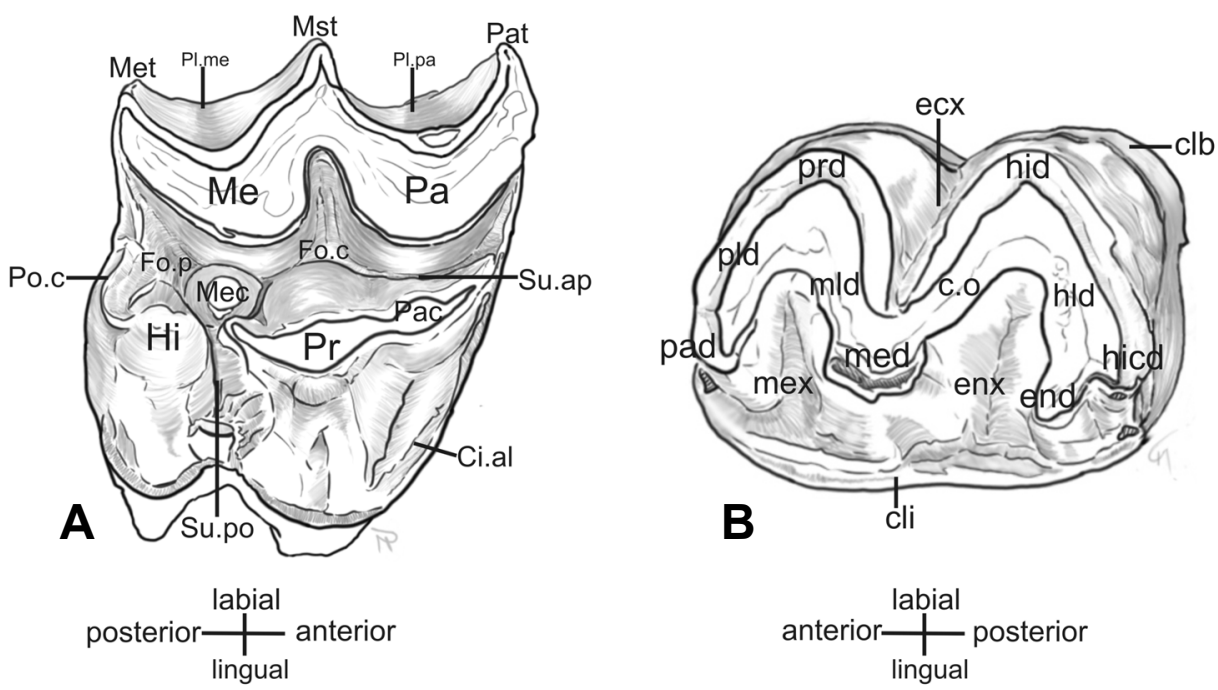

Figura 2. Nomenclatura dentaria de los Proterotheriidae (modificado de Soria, 2001). A, esquema de un molar superior; B, esquema de un molar inferior.

Figure 2. Dental nomenclature of Proterotheriidae (modified from Soria, 2001). A, upper tooth scheme; B, lower tooth scheme.

Extended diagnosis. (From Pascual et al., 1966; Soria, 2001). Deciduous upper premolars longer than wide, and paracone and metacone folds present. P3-P4 molariform and quadrangular. P3-M3 with paracone and metacone folds generally conspicuous. Upper molars with welldeveloped hypocone, separated from the protocone by a posterolingual groove as in Neobrachytherium intermedium and Thoatheriopsis mendocensis. M1-M2 generally with protocone large and metaconule isolated, bunoid. Paraconule, protocone and metaconule joined with wear. M3 reduced, trapezoidal, without hypocone. Deciduous and permanent lower premolars elongated. Lower molars with cristid obliqua at metaconid level as Diplasiotherium pampa and Neobrachytherium ullumense. Entoconid closer or joined to hypoconulid with wear, mainly in $\mathrm{m} 3$, different from Neobrachytherium ameghinoi. Hypoconulid of $m 3$ tending to form a third lobe, less marked than in Tetramerorhinus. Presence and development of cingula variable.

Diagnosis ampliada. (A partir de Pascual et al., 1966; Soria, 2001). Premolares superiores deciduos con el diámetro anteroposterior mayor que el transverso y pliegues de paracono y metacono presentes. P3-P4 molariformes y cuadrangulares. P3-M3 con pliegues de paracono y metacono generalmente conspicuos. Molares superiores con hipocono robusto separado del protocono por un surco posterolingual como en Neobrachytherium intermedium y Thoatheriopsis mendocensis. M1-M2 generalmente con protocono grande y metacónulo bunoide, aislado. Paracónulo, protocono y metacónulo unidos por el desgaste. M3 pequeño, trapezoidal, sin hipocono. Premolares inferiores deciduos y definitivos alargados anteroposteriormente. Molares inferiores con la cristida obliqua a nivel del metacónido como en Diplasiotherium pampa y Neobrachytherium ullumense. Entocónido cercano o unido al hipoconúlido por el desgaste, fundamentalmente en el m3, a diferencia de Neobrachytherium ameghinoi. Hipoconúlido del $\mathrm{m} 3$ tendiente a formar un tercer lóbulo, menos marcado que en Tetramerorhinus. Presencia y desarrollo de los cíngulos variable.

\section{Brachytherium cuspidatum Ameghino, 1883b}

(Figuras 3A-K; Apéndice 1; Tablas 1-2)

1883b Brachytherium cuspidatum Ameghino, p. 289; 1885, p. $105 ; 1886$, p. 154,1889 , p. 357 ; Pascual, 1966, p. 162 , lám. 71, fig. A; Delupi de Bianchini \& Bianchini, 1971, p. 11, lám. 2, fig. 1 .

1891 Proterotherium gradatum Ameghino, p. 137-138, fig. 35. 1904a Brachytherium gradatum Ameghino, p. 481-483, fig. 626. 1971 Licaphrium mesopotamiense Delupi de Bianchini \& Bianchini, p. 14-15, lám. 2, fig. 2.

1971 Thoatherium sp. Delupi de Bianchini \& Bianchini, p. 18 , lám. 2, fig. 3 .

2001 Lophogonodon gradatum Soria, p. 88, fig. 26.

1904a Lophogonodon paranensis Ameghino, p. 527, figs. 628-629; 1904b, p. 147-148; Kraglievich, 1934, p. 41; Soria 2001, p. 91.

1971 Epitherium paranensis Delupi de Bianchini \& Bianchini, p. 15-17, lám. 1, figs. 7 y 8 .

2001 Neobrachytherium ameghinoi Soria (partim: MACN PV 14306, p. 80).

Diagnosis. Igual que la del género por monotipia.

Holotipo. MLP 69-XII-2-4, fragmento mandibular derecho con dp2-dp4 y m1 en erupción.

Material referido. Detallado en el Apéndice 1.

Distribución geográfica y estratigráfica. La misma que la del género.

Descripción. Dentición superior. Los premolares superiores deciduos (MLP 81-XI-29-8 y MACN A-11000a; Figuras $3 \mathrm{~A}, \mathrm{~B})$ presentan el diámetro anteroposterior mayor que el transverso, las cúspides linguales son más bajas que las labiales y están presentes los pliegues del paracono y del 
metacono. El DP1 presenta una cúspide labial (paracono?) y se destaca el metastilo. En vista oclusal, se ensancha hacia atrás, el cíngulo lingual comienza en la región anterior y continúa por toda la cara interna del diente. El DP2 es similar al anterior, pero con el parastilo y el metastilo más desarrollados. Presenta un borde lingual agudo, no tan basal como en el DP1, que alcanza la región del parastilo y forma la pared anterior del diente. Un pequeño surco divide el diente en dos valles, siendo el anterior más estrecho que el posterior. DP3 y DP4 son similares entre sí, pero el primero es más pequeño y más largo que ancho. En ambos, el mesostilo está más desarrollado. Se distinguen protocono, paracónulo y metacónulo unidos por el desgaste y dispuestos en ángulo casi llano (MLP 81XI-29-8) o recto (MACN A 11000a). Se observa un esbozo de cíngulo anterolingual en DP3 y bien desarrollado en DP4. Entre los DP4 de MLP 81-XI-29-8 y MACNA-11000a existen diferencias mínimas. En el primero, el metacónulo no está desarrollado completamente y el surco posterolingual no alcanza a separar totalmente al hipocono (característica de los molares superiores de este género), aunque aparta esta cúspide del protocono. Además, MACN A-11000a es de tamaño mayor (Tabla 1). Entre los premolares superiores, el P2 (MACN A-5865) presenta un contorno triangular, angosto anteriormente y más largo que ancho. El mesostilo es el único pliegue externo marcado. Lingualmente está dividido en dos lóbulos, en el anterior se aprecia un protocono incipiente y es más pequeño que el posterior. Los P3-P4 (Figura 3C) son cuadrangulares y el desarrollo de los pliegues labiales es variable. Los M1-M2 (Figuras 3C-E) presentan el hipocono robusto separado del protocono por un surco posterolingual y los pliegues del paracono y del metacono pueden estar presentes o no. El cíngulo anterolingual puede prolongarse hasta alcanzar el paracono y formar la pared anterior del diente. Por lo general, el protocono es una cúspide notable, unida por el desgaste al paracónulo y al metacónulo. El M3 (Figura 3E) es notoriamente más pequeño, trapezoidal, con la cara anterior más ancha que la posterior; carece de hipocono y presenta el parastilo más destacado que los demás estilos.

Dentición inferior. Entre las piezas deciduas sólo se conoce la serie dp2-dp4. El dp2 (MLP 69-XII-2-4, Figura 3F) presenta una cúspide labial (protocónido?). En vista lingual, una columna central, correspondiente al metacónido, separa dos regiones. La región anterior presenta una bifurcación acorde con un parastílido (labial) y un paracónido (lingual). En la región posterior, un contrafuerte lingual se extiende hacia la región posterior del diente y limita una fosa que queda abierta por la parte posterior. El dp3 tiene el trigónido más largo que el talónido. El paracónido y el parastílido están diferenciados y son aproximadamente de la misma altura. Los dp4 presentan los lóbulos prácticamente del mismo tamaño (MLP 69-XII-2-4, MACN PV 13172) o el trigónido es apenas más corto que el talónido (MACN PV 1208, MACN PV 9155). El metacónido es la cúspide más conspicua. El entocónido y el hipoconúlido están unidos en la base como en los dp3. Los cíngulos en dp3 y dp4 presentan un desarrollo variable. Respecto a los premolares inferiores definitivos, el único p1 estudiado (MACN PV 4677) presenta dos raíces, es pequeño, muy estrecho buco-lingualmente e imbricado con el p2. No se distingue el cíngulo labial y el lingual es visible en el lóbulo anterior. El p2 y el p3 (Figura 3G) presentan generalmente el trigónido alargado anteroposteriormente, paracónido y parastílido. El p3 MLP 81-XI-29-2 carece de parastílido, tratándose posiblemente de una variación individual. El trigónido es más estrecho y alargado que el talónido. Por la cara labial, el trigónido está más elevado que el talónido. La presencia del entocónido es variable. Los p4 carecen de parastílido y el talónido es más ancho y largo que el trigónido, aunque en algunos casos pueden tener igual tamaño. El entocónido, por lo general, está presente y unido al hipoconúlido. El metacónido es conspicuo y elevado, y los cíngulos presentan desarrollo variable como en p3. Los molares inferiores presentan el entocónido cercano o unido al hipoconúlido (Figura 3G). El m3 presenta el entocónido y el hipoconúlido muy cercanos, unidos en la base. La presencia y el desarrollo de los cíngulos son muy variables. El ejemplar MACN PV 9141 está muy gastado, pero la unión en el m3 del entocónido al hipoconúlido y la tendencia a formar un tercer lóbulo permiten su asignación a Brachytherium cuspidatum. MACN PV 4009 tiene menos desgaste y el entocónido del m3 no se une al hipoconúlido, pero su posición muy cercana (no central en el talónido como en Neobrachytherium ameghinoi) y la curvatura aguda del talónido a la altura del hipocónido permiten determinarlo, con reservas, como B. cuspidatum. La mayoría de los molares inferiores presentan cuatro raíces. No obstante, algunos ejemplares (MACN PV 14302, MACN PV 9141, MACN PV 3962 y MLP 70-I-10-3) presentan una quinta raíz correspondiente al lóbulo posterior del $\mathrm{m} 3$ y coincidente con el mayor tamaño del diente.

Comentarios. Ameghino (1883b) creó el género Brachytherium con la especie tipo B. cuspidatum Ameghino, 1883, a partir de un fragmento mandibular juvenil con dp2dp4 y m1 en erupción. Soria (2001) consideró este taxón como nomen dubium, porque no logró asociar el holotipo a ninguno de los dos conjuntos de ejemplares adultos (previamente atribuidos a Brachytherium) reconocidos por él. Por ello, reunió parte de los restos en el género nuevo Neobrachytherium Soria, 2001, por un lado, y en Lophogonodon Ameghino, 1904a, por otro (Schmidt, 2011). Dentro de Lophogonodon distinguió las especies $L$. paranensis Ameghino, 1904a, y L. gradatum (Ameghino, 1891). La única diferencia que halló entre ellas fue el tamaño (alrededor de un 13,5\% mayor la primera), careciendo de diferencias morfológicas significativas (Soria, 2001).

Aquí se propone anular la condición de nomen dubium para Brachytherium cuspidatum, considerando el notable parecido morfológico y métrico que manifiesta el holotipo, fundamentalmente el dp4, con ejemplares inéditos (MACN PV 9155, MACN PV 9156, MAS PALEO-VERT 400, MAS PALEO-VERT 401; Schmidt, 2013; Figuras 3H-K) y con el revisado por Delupi de Bianchini \& Bianchini (1971), MACN PV 13172, asignados a tal especie. Asimismo, esta dentición decidua se asocia con la de los ejemplares adultos atribuidos fundamentalmente al género Lophogonodon. De hecho, los ejemplares MACN PV 9155, MACN PV 9156 y 


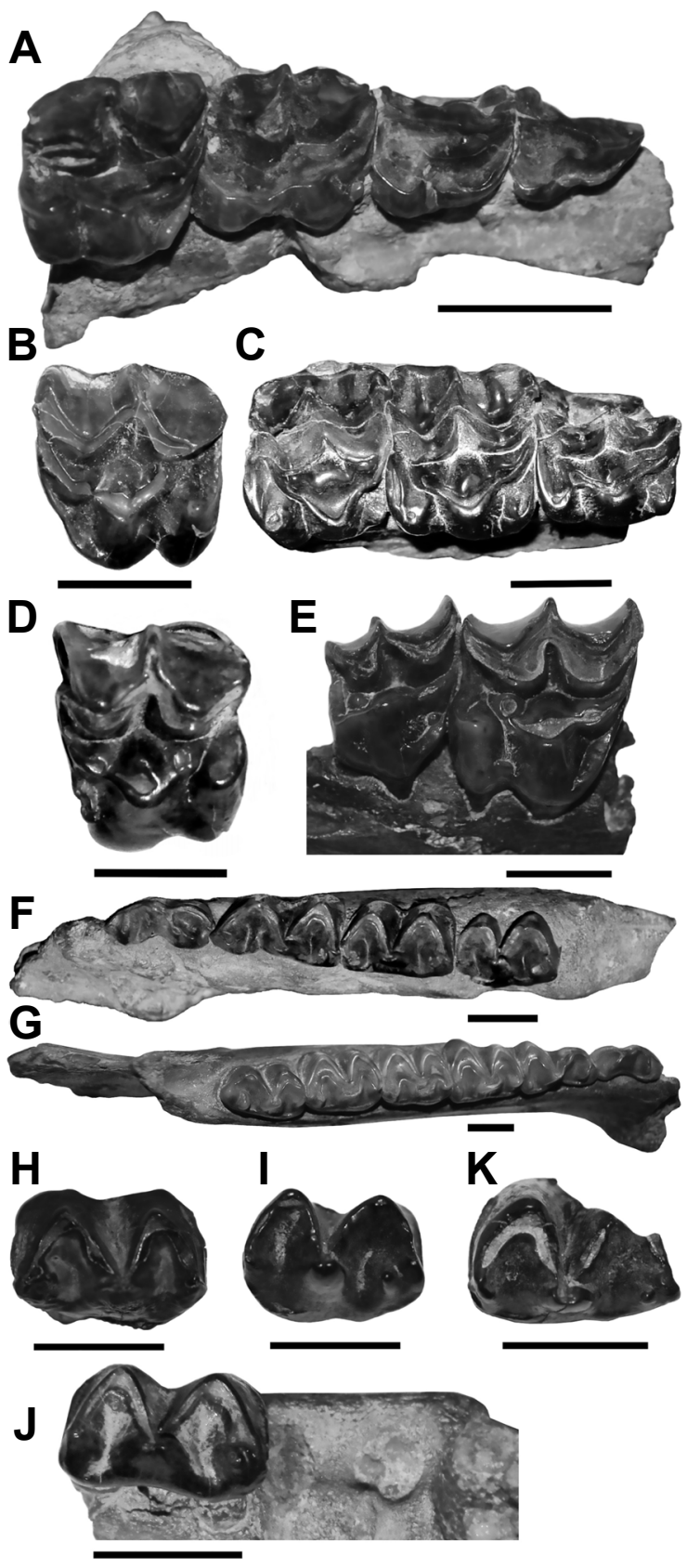

Figura 3. A-K, Brachytherium cuspidatum. A, MLP 81-XI-29-8, fragmento de maxilar derecho con DP1-DP4; B, MACN A-11000a (holotipo de Lophogonodon paranensis), DP4 izquierdo; C, MLP 69-XII-2-11, P3-M1 derechos; D, MACN A-5864, M1 o M2 izquierdo; E, MACN PV 14303, porción de maxilar derecho con M2-M3; F, MLP 69-XII-2-4 (holotipo), fragmento mandibular derecho con dp2-dp4 y m1 en erupción; G, MLP 12-1483, fragmento de rama mandibular izquierda con p2-m3; H, MACN PV 9155, dp4 izquierdo; I, MACN PV 9156, dp4 derecho; J, MAS PALEO-VERT 400, fragmento mandibular derecho con dp4; K, MAS PALEO-VERT 401, dp4 derecho. Todas en vista oclusal. Escalas $=1 \mathrm{~cm}$.

Figure 3. A-K, Brachytherium cuspidatum. A, MLP 81-XI-29-8, maxillary fragment with DP1-DP4; B, MACNA-11000a (holotype of Lophogonodon paranensis), left DP4; C, MLP 69-XII-2-11, right P3-M1; D, MACNA-5864, left M1 or M2; E, MACN PV 14303, right maxillary fragment with M2-M3; F, MLP 69-XII-2-4 (holotype), right mandibular fragment with dp2-dp4 y $\mathrm{m} 1$ erupting; G, MLP 12-1483, left mandibular ramus with $\mathrm{p} 2-\mathrm{m} 3$; H, MACN PV 9155, left dp4; I, MACN PV 9156, right dp4; J, MAS PALEOVERT 400, right mandibular fragment with dp4; K, MAS PALEO-VERT 401 , right dp4. All in occlusal views. Scale bars $=1 \mathrm{~cm}$.
MACN PV 13172 habían sido determinados preliminarmente como Lophogonodon gradatum (Schmidt, 2013). Entre los ejemplares que Soria (2001) reconoció como L. paranensis, dos de ellos presentan dientes deciduos (MLP 12-110a; MACN PV 1208) de tamaño mayor, pero semejantes morfológicamente a los mencionados anteriormente.

Los ejemplares adultos que se relacionan con estos deciduos presentan caracteres morfológicos homogéneos que no apoyan la diferenciación específica defendida por Soria (2001) para el género Lophogonodon. Por lo tanto, el estudio comparativo realizado permite considerar todo el material asignado previamente a Lophogonodon, incluyendo al holotipo de Brachytherium cuspidatum (especie tipo de Brachytherium) como un único taxón. Se anula así la condición de nomen dubium establecida por Soria (2001), teniendo este taxón nominal prioridad sobre Lophogonodon.

El holotipo de Proterotherium gradatum (MACN A-5865) corresponde a un fragmento de maxilar izquierdo con parte posterior del P1 y P2-P3 completos y el de Lophogonodon paranensis (MACN A-11000a) se trata de un DP4 izquierdo aislado. Si bien representan piezas superiores definitivas y deciduas, respectivamente - no comparables -, estos ejemplares comparten, no obstante, la presencia de pliegues del paracono y del metacono al igual que el ejemplar MLP 81-XI-29-8 (fragmento de maxilar derecho con DP1-DP4). Este carácter valida el agrupamiento de los tres ejemplares mencionados bajo una misma entidad taxonómica. Además, estos pliegues no están presentes en los ejemplares definitivos asignados a Neobrachytherium ameghinoi, pero sí en los de $P$. cervioides con el que otras diferencias morfológicas los separan (ver diagnosis). La asociación de los holotipos de $P$. gradatum y de L. paranensis con el holotipo de Brachytherium cuspidatum (MLP 69-XII-2-4, fragmento mandibular derecho con dp2dp4 y m1 en erupción) se ha realizado en función de una correlación de tamaño y gracilidad (considerando el mismo principio unificador seguido por Riggs \& Patterson, 1939, p. 155-156, y posteriormente por Soria, 2001, p. 84, para $N$. morenoi, por ejemplo). Asimismo, la asociación entre los ejemplares inferiores reconocidos tradicionalmente como $L$. paranensis con el holotipo B. cuspidatum se funda en el parecido morfológico de aquellos ejemplares que conservan piezas deciduas y definitivas (MLP 12-110a y MACN PV 1208), pero que son de tamaño mayor. De esta manera, queda justificada la asociación de las piezas superiores (tipos de los sinónimos de B. cuspidatum) con el holotipo de B. cuspidatum.

Dimorfismo sexual. Entre los vertebrados y, en particular, los mamíferos, muchas veces las diferencias de tamaño son indicadoras de dimorfismo sexual (Short \& Balaban, 1994 en Loison et al., 1999; McDonald, 2006). Los rumiantes muestran con frecuencia dimorfismo sexual en el tamaño corporal, los cuernos y el desarrollo de los caninos superiores cuando están presentes. En el registro fósil, las diferencias en el tamaño y algunos caracteres osteológicos como los mencionados también son susceptibles de utilizarse como indicadores de dimorfismo sexual (McDonald, 2006). Este dimorfismo permite realizar 
inferencias de comportamiento y estructura social, al tiempo que tiene importantes implicancias taxonómicas, ya que la existencia de una especie fósil que presenta dimorfismo sexual puede derivar en la identificación incorrecta de dos especies distintas o subespecies en lugar de un solo taxón (Kurtén, 1969). Existen diferentes trabajos que confirman la presencia de dimorfismo sexual en mamíferos fósiles (Mead, 2000; Deng, 2005; Andrés et al., 2008; Sánchez et al., 2010; Azanza et al., 2011, entre otros). Para el caso particular de los Litopterna, la diferencia de tamaño como reflejo de un dimorfismo sexual fue planteada por Scott (1910) y Soria (2001) para especies santacrucenses de Proterotheriidae. Así, por ejemplo, el mayor tamaño de Diadiaphorus robustus Ameghino, 1894, respecto a D. majusculus Ameghino, 1887b, sumado a otras diferencias morfológicas como la separación de los incisivos internos inferiores y la falta de diastema entre los incisivos externos y los caninos, fue considerado un caso de dimorfismo sexual, correspondiendo el mayor tamaño a los machos (Soria, 2001, p. 70).

En el caso de Tetramerorhinus lucarius Ameghino, 1894, Soria (2001, p. 47) consideró como su sinónimo a Licaphrium proclivum Ameghino, 1894 e interpretó que la presencia o ausencia de diastema se debía al dimorfismo sexual reflejado en el tamaño de los incisivos externos, que serían más gráciles y pequeños en las hembras, dando lugar al mencionado diastema. Para Thoatherium minusculum Ameghino, 1887b, sostuvo que existen diferencias de tamaño más acentuadas que en otras especies de otros géneros y se repite la presencia de individuos con incisivos inferiores externos de diferente tamaño.

Entre los proterotéridos de Entre Ríos asignados previamente al género Lophogonodon, ninguno de los restos mandibulares conserva las piezas dentarias anteriores, por lo que no se puede verificar el tipo de dimorfismo reconocido en los tres géneros santacrucenses. No obstante, sostener la presencia de dos especies del mismo género en la Formación Ituzaingó en función de la diferencia de tamaño entre ellas, cuando no manifiestan variabilidad morfológica alguna, no resulta plenamente justificado. Tampoco es factible atribuirla a una variación ontogenética, ya que la mayoría de los restos asignados a la especie de tamaño menor (Lophogonodon gradatum) son de individuos adultos. Por lo tanto, se puede hipotetizar que el distinto tamaño entre L. paranensis y L. gradatum se debe a la existencia de dimorfismo sexual intraespecífico, tal como se ha sugerido para otros proterotéridos. El resultado de los análisis discriminantes arrojó datos que apoyan esta idea (Apéndice 2). En todos los casos, la prueba de homogeneidad de matrices de covarianzas arrojó valores de p que sugieren el cumplimiento de este supuesto. La primera función discriminante estandarizada por las varianzas comunes muestra que, en la mayoría de los casos, la variable más importante para la discriminación es la longitud de las piezas dentarias. Asimismo, la tabla de clasificación cruzada señala que tanto los ejemplares de Lophogonodon paranensis (Brachytherium cuspidatum tamaño mayor) como Lophogonodon gradatum (B. cuspidatum tamaño menor) fueron clasificados correctamente, observándose una tasa de error de clasificación igual a $0 \%$. Esto último, también se observa en la separación de nubes de puntos (Figuras 4A-D) y se interpreta como una evidencia a favor de la hipótesis de la diferenciación sexual.

En consecuencia, se considera que Lophogonodon paranensis y L. gradatum son sinónimos. A la vez, se integran en el mismo taxón los restos de dentición decidua que incluyen al holotipo de Brachytherium cuspidatum. Por tanto, como este taxón tiene prioridad, Lophogonodon resulta sinónimo de Brachytherium y ambas especies de Lophogonodon son sinónimas de B. cuspidatum.

Discusión. Brachytherium cuspidatum comparte con Neobrachytherium intermedium de Catamarca, Thoatheriopsis mendocensis de Mendoza y Epitherium laternarium Ameghino, 1888 de Monte Hermoso el surco profundo posterolingual que separa el protocono del hipocono en M1M2, la presencia del metacónulo en el P3 y el M3, del hipocono en P3 y P4, y de los cíngulos labiales en los molares superiores (visibles también en Eoauchenia primitiva Ameghino, 1887a de Monte Hermoso). A su vez, B. cuspidatum, al igual que T. mendocensis, N. ameghinoi, Ep. laternarium y Eo. primitiva, tiene el parastilo más desarrollado que el mesostilo en M1-M3 (M1 y M3 en N. ameghinoi), mientras que el mesostilo es el más desarrollado en $N$. intermedium.

En Brachytherium cuspidatum, los pliegues del paracono y del metacono aparecen poco desarrollados como en algunos ejemplares de Neobrachytherium intermedium (MACN PV 8432, PVL 3152 y FMNH P 14500), mientras que no se observan en Thoatheriopsis mendocensis, Epitherium laternarium y Eoauchenia primitiva. B. cuspidatum carece de hipocono en el M3, a diferencia de $T$. mendocensis y $N$. intermedium, estando reducido en $N$. ameghinoi. El p3 de B. cuspidatum (MLP 81-XI-29-2) comparte con el de Epecuenia thoatherioides Cabrera, 1939 (MLP 37-III-7-4), del Huayqueriense de Buenos Aires (Formación Epecuén), la ausencia de bifurcación anterior en el trigónido. No obstante, se diferencian por la forma del talónido, más triangular en E. thoatherioides y no tan aguda en B. cuspidatum.

La corona de los molares inferiores de Brachytherium cuspidatum (y del resto de los taxones entrerrianos) es relativamente más baja que la de Diplasiotherium robustum Rovereto, 1914, de Monte Hermoso (Mioceno tardío-Plioceno temprano, de Buenos Aires). Además, esta última especie presenta lófidos más gruesos que las especies huayquerienses (salvo Diplasiotherium pampa Soria, 2001, de Salinas Grandes de Hidalgo, La Pampa) y el entocónido del m3 agudo y proporcionalmente más pequeño que el de otros proterotéridos que presentan esta cúspide (Soria, 2001).

$$
\text { Neobrachytherium Soria, } 2001
$$

Especie tipo. Licaphrium intermedium Moreno \& Mercerat, 1891.

Distribución geográfica y estratigráfica. Provincias de Catamarca, San Juan, Mendoza, Entre Ríos, La Rioja y Buenos Aires. Edades mamífero Chasiquense a Montehermosense, Mioceno tardío-Plioceno. Formaciones Corral Quemado, Ullum, Huayquerías, Ituzaingó, Salicas y Arroyo Chasicó. 

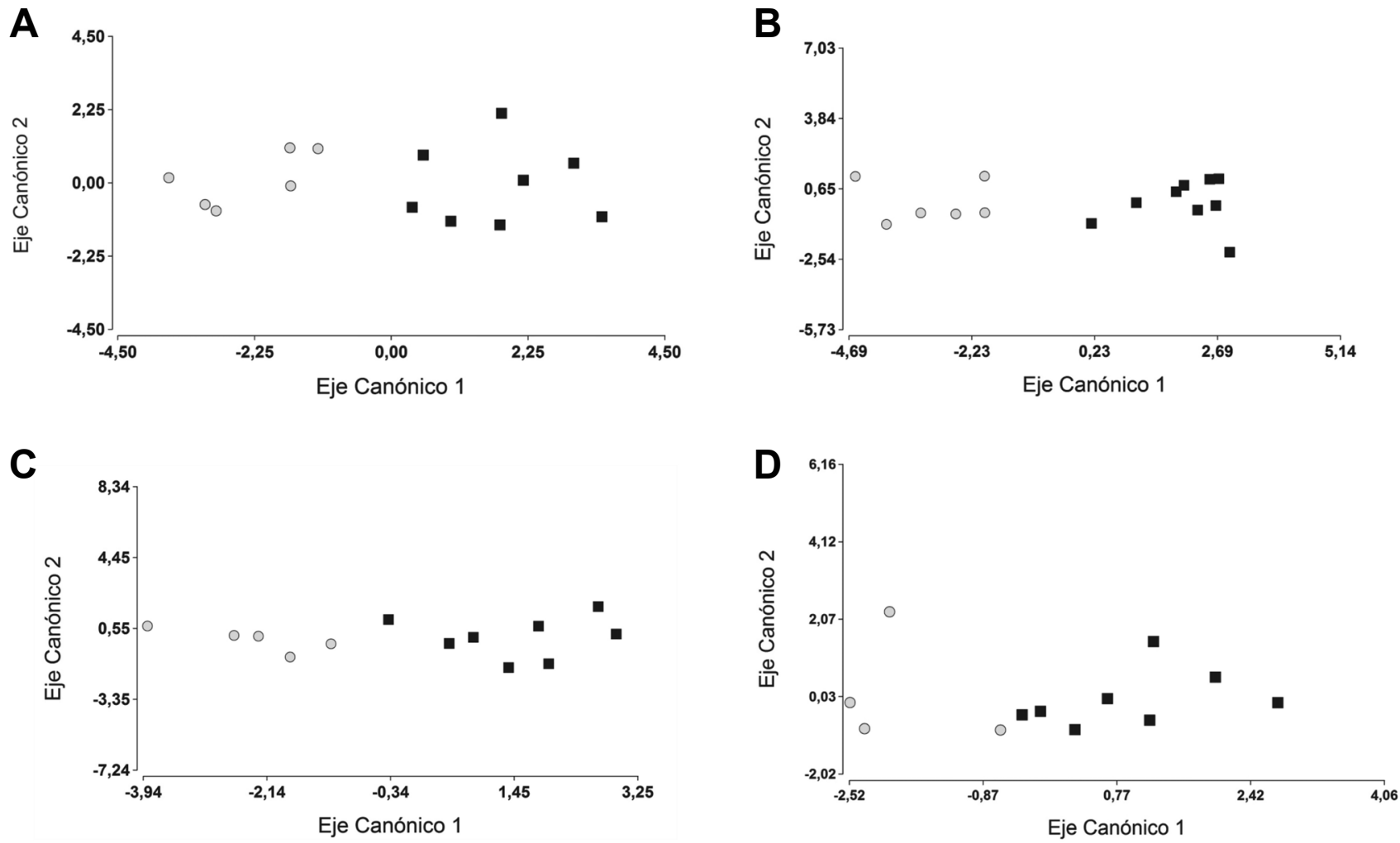

Figura 4. Análisis discriminantes de dientes inferiores (p3-m3) de Brachytherium cuspidatum. A, gráfico comparando p3-p4; B, gráfico comparando p4-m1; C, gráfico comparando m1-m2; D, gráfico comparando m2-m3. Los círculos grises (B. cuspidatum de tamaño menor) y cuadrados negros (B. cuspidatum de tamaño mayor) apoyan la separación en dos grupos dentro de la misma especie.

Figure 4. Discriminant analyses of lower teeth (p3-m3) of Brachytherium cuspidatum. A, graphic comparing p3-p4; B, graphic comparing p4$\mathrm{m} 1$; C, graphic comparing $\mathrm{m} 1-\mathrm{m} 2$; D, graphic comparing $\mathrm{m} 2-\mathrm{m} 3$. Light spots (B. cuspidatum smaller) and dark squares (B. cuspidatum larger) support the separation into two groups within the same species.

Extended diagnosis. (After Soria, 2001). Premolars and molars with hypsodonty degree similar to Brachytherium and Thoatheriopsis; more hypsodont than Proterotherium, but less than Epitherium and Eoauchenia. Upper premolars and molars quadrangular. Parastyle and mesostyle more developed than metastyle. Anteroposterior groove deep. M1-M2 with metaconule less developed than Brachytherium. Metaconule in M3 present or not; hypocone present in contrast with Brachytherium. Lower molars with paraconid close to metaconid. Entoconid of 33 joined to hypoconulid or not. Cristida obliqua in $m 3$ at metaconid or metalophid level. Diagnosis ampliada. (A partir de Soria, 2001). Premolares y molares con un nivel de hipsodoncia semejante a Brachytherium y Thoatheriopsis; más hipsodontes que Proterotherium, pero menos que Epitherium y Eoauchenia. Yugales superiores de contorno cuadrangular. Parastilo y mesostilo más desarrollados que metastilo. Surco anteroposterior profundo. M1-M2 con metacónulo menos desarrollado que Brachytherium. Metacónulo en M3 presente o no, y con hipocono, a diferencia de Brachytherium. Molares inferiores con paracónido cercano al metacónido. Entocónido del $\mathrm{m} 3$ unido o no al hipoconúlido. Cristida obliqua en $\mathrm{m} 3$ a la altura del metacónido o del metalófido.
Neobrachytherium ameghinoi Soria, 2001

(Figuras 5A-C; Apéndice 1; Tablas 1-2)

2001 Neobrachytherium ameghinoi Soria, p. 80, fig. 20. 1885 Brachytherium cuspidatum (partim) Ameghino, p. 105$110 ; 1889$, p. 561-565 (partim), lám. 23, figs. 20-21; 1904a, p. 481-482 (partim), figs. 625-627 (non Ameghino, 1883b); Pascual, 1966, p. 162 (lám. 71, B).

Distribución geográfica y estratigráfica. Barrancas del río Paraná, Entre Ríos. "Mesopotamiense", base de la Formación Ituzaingó (Mioceno tardío).

Holotipo. MACN PV 14308, fragmento mandibular derecho con $\mathrm{p} 4-\mathrm{m} 3$.

Extended diagnosis. (From Soria, 2001). Upper molars quadrangular, without paracone and metacone folds. Anterolingual cingulum defining a fossette similar to Neobrachytherium morenoi. Protocone joined to paraconule in a continuous surface. Metaconule reduced and joined to protocone-hypocone conjunction, different from Neobrachytherium intermedium. M3 trapezoidal with metaconule and hypocone reduced, different from $\mathrm{N}$. intermedium. Entoconid bunoid in $\mathrm{m} 3$, separated from the hipoconulid, and centered in the talonid, different 
from N. ullumense, where is closer to hypolophulid, and $\mathrm{N}$. intermedium where is connected to hypoconulid by a crest. The cristida obliqua in $m 3$ rests on metalophid.

Diagnosis ampliada. (A partir de Soria, 2001). Molares superiores de contorno cuadrangular, sin pliegues de paracono y metacono. El cíngulo anterolingual define una foseta similar a la de Neobrachytherium morenoi. Protocono unido al paracónulo en una superficie continua. Metacónulo reducido y unido a la conjunción protocono-hipocono, a diferencia de Neobrachytherium intermedium. M3 trapezoidal con metacónulo e hipocono reducidos, a diferencia de $N$. intermedium. Entocónido bunoide en $\mathrm{m} 3$, separado del hipoconúlido y en el centro del talónido, a diferencia de $N$. ullumense, donde está más cercano al hipolofúlido, y de $N$. intermedium donde se conecta al hipoconúlido por una cresta. La cristida obliqua del m3 descansa sobre el metalófido.

Material referido. Detallado en el Apéndice 1.

Descripción. Dentición superior. Los molares superiores de Neobrachytherium ameghinoi son cuadrangulares, carecen de pliegues de paracono y metacono y las paredes linguales son verticales. El ejemplar MACN A- 1401 (MLP M-177, calco de M1 o M2, Figura 5A) presenta poco desgaste y el protocono está unido al paracónulo en una superficie continua. El metacónulo está reducido y unido a la conjunción protocono-hipocono, por lo que el surco posterolingual no separa al hipocono como en Brachytherium. El surco anteroposterior es profundo. El paracónulo se prolonga anterolabialmente y el cíngulo anterolingual delimita una depresión. Los ejemplares MACN PV 9150 y MACN PV 13212 están muy desgastados. Presentan el parastilo más desarrollado y más separado del mesostilo y el metastilo; tienen cíngulos anterolingual y labial; hay una pequeña foseta central y otra posterior. El M3 (MLP M-178, Figura 5B; ver Schmidt, 2011 sobre la identificación de este ejemplar) presenta el parastilo más desarrollado. Es de contorno trapezoidal, con la región anterior más ancha que la posterior. Se aprecia una superficie continua de desgaste entre protocono, paracónulo y metacónulo. A diferencia de Brachytherium, presenta el hipocono reducido y un tamaño mayor.

Dentición inferior. El holotipo (MACN PV 14308, Figura 5C) conserva la serie p4-m3. El p4 presenta el lóbulo posterior más ancho que el anterior, el metacónido elevado y el entocónido conspicuo, unido por la base al hipoconúlido. $\mathrm{El} \mathrm{m1} \mathrm{es} \mathrm{el} \mathrm{más} \mathrm{gastado} \mathrm{de} \mathrm{la} \mathrm{serie.} \mathrm{Es} \mathrm{similar} \mathrm{al} \mathrm{m2,} \mathrm{pero}$ los valles linguales están apenas marcados y el ectofléxido es poco profundo. En ambos, el valle anterior (metafléxido) es más abierto que el posterior. El $\mathrm{m} 3$ es más comprimido bucolingualmente. El valle posterior (entofléxido) es más abierto y en el centro se ubica el entocónido. El lóbulo posterior presenta el borde labial más agudo y la pared posterior manifiesta una suave concavidad, sin diferenciar un tercer lóbulo. En todas las piezas los cíngulos linguales están restringidos a la base de los valles y los labiales rodean cada diente a modo de dentículos pequeños. No se conocen ejemplares deciduos. El otro p4 asignado a esta especie (MLP 12-102a) es similar al descripto. En el resto de los ejemplares reconocidos como Neobrachytherium ameghinoi (ver Apéndice 1), los molares inferiores presentan entofléxidos amplios y ectofléxidos poco profundos. El $\mathrm{m} 3$ se diferencia del de Brachytherium por tener el entocónido independiente del hipoconúlido y en el centro del entofléxido. El desarrollo de los cíngulos varía entre los ejemplares.

Discusión. El género Neobrachytherium es el resultado de una situación particular de sinonimias propuestas por Soria (2001), que lo llevaron a fundar un nuevo género a fin de no crear confusión entre los ya existentes, puesto que en él incluyó material asignado previamente a Brachytherium, Licaphrium y Proterotherium. Consideró, además, la posibilidad de que Epecuenia - del Mioceno tardío de Buenos Aires (Formación Epecuén) - sea el género válido para todas las especies asignadas por él a Neobrachytherium, dado que aquél se basa en material postcraneano sin dentición asociada y los huesos presentan semejanzas con restos homólogos asignados a $N$. intermedium.

Soria (2001) reconoció cuatro especies de Neobrachytherium: N. intermedium (Moreno \& Mercerat, 1891) y N. morenoi (Rovereto, 1914), del Montehermosense de Catamarca (Formación Corral Quemado), N. ameghinoi del "Mesopotamiense" de Entre Ríos (Formación Ituzaingó) y N. ullumense Soria, 2001 del Chasiquense de San Juan (Formación Loma de las Tapias), reconocido también en Arroyo Chasicó (Buenos Aires; Cerdeño, 2003); asimismo, reconoció Neobrachytherium sp. en la Formación Huayquerías de Mendoza a partir de un material craneal muy deteriorado asociado a restos postcraneanos (MACN PV 8477). Recientemente, Brandoni et al. (2012) reportaron la presencia del género en la Formación Salicas (La Rioja), unidad considerada dentro del Mioceno tardío.

Los M1 o M2 de Neobrachytherium ameghinoi (MACN A-1401, MACN PV 9150, MACN PV 13212) presentan un contorno cuadrangular similar al de Neobrachytherium ullumense (MCNAM PV-3222) y Neobrachytherium sp. de Salicas (CRILAR Pv 429). El cíngulo anterolingual delimita una foseta semejante a la que se aprecia en Neobrachytherium morenoi. En $N$. intermedium, en cambio, este cíngulo está más desarrollado y forma un reborde más bien plano. Además, en $N$. ameghinoi está restringido a la región anterior, como en $N$. ullumense, mientras que en $N$. morenoi y $N$. intermedium se extiende hasta casi la base del protocono. La concavidad entre el parastilo y el mesostilo es similar a la de $N$. ullumense. En todas las especies de Neobrachytherium, el surco posterolingual está interrumpido por el metacónulo en mayor o menor medida. Neobrachytherium ameghinoi (MLP M-178) y $N$. intermedium poseen metacónulo en el M3, a diferencia de $N$. ullumense. Sobre el M3 MLP M-178 de Neobrachytherium ameghinoi, es importante destacar aquí la presencia de un hipocono débil en esta pieza, ausente en Brachytherium cuspidatum.

Respecto a los molares inferiores, Neobrachytherium ameghinoi, Brachytherium cuspidatum y Epitherium laternarium comparten el paralófido de $\mathrm{m} 1-\mathrm{m} 2$ desarrollado y terminado lingualmente. No obstante, el $\mathrm{m} 1 \mathrm{de} N$. ameghinoi y B. cuspidatum carece de una fosétida central circular en el trigónido, de entocónido unido a la cristida obliqua por un entolófido y de trigónido de contorno labial redondeado, rasgos que se observan en E. laternarium (MACN A-211). 
Por otro lado, Neobrachytherium ameghinoi manifiesta la particularidad de tener el entocónido bunoide y central en el entofléxido del m3. En Neobrachytherium ullumense (MCNAM PV-3223), si bien está separado del hipolófido, no ocupa una posición central y el trigónido es más cerrado. Para Neobrachytherium intermedium, Soria (2001) indicó que el $\mathrm{m} 3$ tiene el entocónido unido al hipoconúlido por una cresta lingual. Esta característica es observable en el holotipo MLP 12-316 (actualmente extraviado), según el esquema figurado por Soria (2001), pero no ocurre lo mismo en los ejemplares FMNH P 14500 (calco depositado en el Museo de La Plata) y MACN PV 8434 (que sólo conserva el talónido); en ellos, el entocónido está separado del hipoconúlido y ocupa una posición más lingual que en $N$. ullumense. Los restos dentarios inferiores de $N$. morenoi no conservan el $\mathrm{m} 3$, pero una particularidad del m1 (PVL 3196) es la presencia de un pequeño parastílido no observado en ninguna otra especie, respondiendo posiblemente a una variante individual (Soria, 2001). En los m3 de $N$. ameghinoi y $N$. intermedium, la cristida obliqua termina sobre el metalófido; en $N$. ullumense y Diplasiotherium pampa, en cambio, lo hace a la altura del metacónido. Los molares inferiores de $N$. ameghinoi presentan los lófidos menos robustos y los fléxidos más abiertos que los de $N$. intermedium y D. pampa (fundamentalmente el ectofléxido en el caso de esta última especie).

Las medidas indican que la especie entrerriana es ligeramente más grande que las otras tres del mismo género. A su vez, Neobrachytherium intermedium es apenas mayor que $N$. morenoi y $N$. ullumense (Tablas 1-2).

La asociación entre las piezas superiores e inferiores del material reunido bajo la denominación Neobrachytherium ameghinoi sigue el mismo criterio establecido por Soria (2001) para las demás especies del género, el cual se basa en una correlación de tamaño.

\section{Proterotherium Ameghino, 1883b}

Especie tipo. Proterotherium cervioides Ameghino, 1883 b.

Distribución geográfica y estratigráfica. Barrancas del río Paraná, Entre Ríos. "Mesopotamiense”, base de la Formación Ituzaingó (Mioceno tardío).

Extended diagnosis. (After Soria, 2001). Labial styles in P4M3 with moderate development. Paracone and metacone folds prominent in all teeth, the metacone fold in M2 less marked. Anteroposterior groove not interrupted by the metaconule as in Paramacrauchenia. Anterolingual cingulum in P4-M2 anteriorly extended. P4-M1 with metaconule bunoid and weak, associated to protocone, more lingual and reduced than in Brachytherium. M2 with ridge-shaped metaconule, associated to protocone. P4-M2 with posterolingual groove separating hypocone from protocone, similar to Brachytherium, Tetramerorhinus or Thoatheriopsis. M1-M2 with hypocone directed to base of metastyle, forming the posterior tooth wall.

Diagnosis ampliada. (A partir de Soria, 2001). Estilos labiales en P4-M2 con desarrollo moderado. Pliegues de paracono y metacono conspicuos en todas las piezas, menos marcado el del metacono en el M2. Surco anteroposterior no interrumpido por el metacónulo, similar a Paramacrauchenia. P4-M2 con cíngulo anterolingual extendido anteriormente. P4-M1 con metacónulo bunoide y débil, asociado al protocono, más lingual y reducido que en Brachytherium. M2 con metacónulo en forma de cresta, asociado al protocono. P4-M2 con un surco posterolingual que separa al hipocono del protocono, recordando a Brachytherium, Tetramerorhinus o Thoatheriopsis. M1-M2 con hipocono proyectado hasta la base del metastilo formando la pared posterior del diente.

Proterotherium cervioides Ameghino, 1883b

(Figuras 5D-E; Apéndice 1; Tablas 1-2)

1883b Proterotherium cervioides Ameghino, p. 291-293; 1886 , p. 160-164; 1889, p. 558-559, lám. 71, fig. 14, lám. 72, fig. 2; 1904a, p. 480-481, fig. 624; Delupi de Bianchini \& Bianchini, 1971, p. 8, lám. 1, figs. 3 y 4; Soria, 1981, p. 49-50; 2001, p. 87, fig. 25.

Distribución geográfica y estratigráfica. Barrancas del río Paraná, Entre Ríos. "Mesopotamiense", base de la Formación Ituzaingó (Mioceno tardío)

Holotipo. MLP 69-XII-2-9, fragmento de maxilar izquierdo con P4-M2 y M3 en erupción.

Diagnosis. Igual que la del género por monotipia.

Material referido. Detallado en el Apéndice 1.

Descripción. El holotipo (Figura 5D) presenta dientes de corona braquiodonte con pliegues labiales marcados (menos marcado el del metacono en el M2) y sin cíngulo labial. La serie P4-M2 tiene los estilos moderadamente desarrollados, protocono e hipocono separados, dejando un surco profundo como en Brachytherium, y el cíngulo anterolingual sin unir al protocono. El P4 y el M1 presentan un metacónulo bunoide y débil asociado al protocono. El surco anteroposterior en P4-M2 no está interrumpido por el metacónulo, como sucede en Paramacrauchenia (Soria, 2001, p. 30, fig. 8a). Esta serie también presenta un surco posterolingual que separa al hipocono del protocono, al igual que en Brachytherium, Tetramerorhinus Ameghino, 1894 o Thoatheriopsis. Los M1-M2 presentan el hipocono proyectado hasta la base del metastilo formando la pared posterior del diente.

En MACN PV 2631 (dp4?, Figura 5E), los valles linguales tienen la misma profundidad y el mismo diámetro bucolingual y los bordes externos pronunciados. El paracónido está desarrollado y hay entocónido. El ectofléxido es amplio y el cíngulo labial está más desarrollado que el lingual.

El astrágalo (MACN PV 4204) presenta la tróclea ligeramente asimétrica con la cresta medial mayor que la lateral. En vista dorsal, una fosa cóncava se ubica en la base del cuello, aunque algo desplazada hacia el costado externo. La articulación distal es convexa, con una expansión medial orientada lateralmente. En la cara ventral, la faceta sustentacular es ligeramente convexa y la ectal es muy cóncava.

Discusión. Ameghino (1883b) dio a conocer el género Proterotherium y su especie tipo, $P$. cervioides, a partir 
de un resto de maxilar (MLP 69-XII-2-9) procedente del "Mesopotamiense" de Entre Ríos. Delupi de Bianchini \& Bianchini (1971) revisaron el material y mencionaron varias diferencias morfológicas que lo separarían de las especies santacrucenses asignadas a Proterotherium. Igualmente, Soria $(1981,2001)$ comprobó que los caracteres dentarios de P. cervioides estaban más cerca de las especies colloncurenses Lambdaconus lacerum y Paramacrauchenia scamnata que de las especies santacrucenses de los géneros Tetramerorhinus, Anisolophus Burmeister, 1885 y Thoatherium.

Las características del holotipo (MLP 69-XII-2-9) permiten diferenciar a Proterotherium cervioides de las otras especies de Entre Ríos. Los pliegues labiales están más desarrollados y las coronas son más bajas que en Brachytherium cuspidatum y Neobrachytherium ameghinoi. El metacónulo es lofoide en M1-M2 y está unido al protocono, mientras que es bunoide y aislado en B. cuspidatum y aparece reducido y unido a la conjunción protocono-hipocono en $N$. ameghinoi (MACN A-1401, M1). MLP 69-XII-2-9 comparte con B. cuspidatum y $N$. ameghinoi la presencia del metacónulo en el M3. En M1-M2, el hipocono está separado del protocono por un surco lingual al igual que en $B$. cuspidatum y Diadiaphorus eversus (M1?).

El astrágalo MACN PV 4204, asignado a Thoatherium sp. por Delupi de Bianchini \& Bianchini (1971), fue determinado por Soria (2001) como Proterotherium cervioides. La morfología de este astrágalo no difiere en general de la del resto de los proterotéridos y su tamaño pequeño fue lo que indujo a Soria a cambiar su atribución taxonómica. Efectivamente, las medidas tomadas de diferentes ejemplares asignados a T. minusculum (Schmidt, 2013) indican que MACN PV 4204 es apenas menor que esta especie. Asimismo, su talla no da lugar a que se pueda incluir en ninguna de las otras especies de Entre Ríos, por lo que se mantiene la asignación a $P$. cervioides.

El dp4? MACN PV 2631 se incluye en este taxón en virtud de que sus medidas manifiestan un tamaño menor al de otros taxones registrados en la misma unidad (Tabla 2). Por lo tanto, siguiendo el mismo razonamiento expuesto anteriormente para los demás taxones y en virtud de la disociación con las piezas superiores que presentan los restos procedentes de este nivel, se mantiene la correlación de este dp4? con el holotipo (MLP 69-XII-2-9) y el astrágalo MACN PV 4204.

En Uruguay, Kraglievich (1930) reconoció Proterotherium berroi a partir de un fragmento distal de húmero izquierdo (MPCN 1554, Col. Berro) procedente de la región de Perico Flaco (Departamento de Soriano), sin procedencia estratigráfica precisa. Según un dibujo publicado por el autor, este ejemplar es morfológicamente similar al ejemplar de Entre Ríos MACN PV 3673 - considerado un Proterotheriidae indet. (Schmidt, 2013) - aunque presenta algo más desarrollado el epicóndilo lateral. Asimismo, las medidas publicadas del diámetro transverso máximo de la extremidad distal y de la tróclea indican que se trata de un ejemplar de tamaño apenas menor que MACN PV 3673. Tampoco presenta diferencias métricas importantes con el húmero de Eoauchenia primitiva (MLP 12-2401), pero es menor que el de Diadiaphorus majusculus (MACN A-9122) (Schmidt, 2013). Si bien autores anteriores (Cione et al., 2000; Cozzuol, 2006 y Schmidt, 2013) consideraron que Proterotherium berroi correspondía a niveles Mio-Pliocenos, Montenegro et al. (2011) indican que en los alrededores del Arroyo Perico Flaco los niveles portadores son asignables a la Formación Dolores (Pleistoceno tardío-Holoceno temprano). De modo que existe la posibilidad de que el húmero en cuestión corresponda, en realidad, a Neolicaphrium Frenguelli, 1921, último representante de la familia (Bond et al., 2001; Ubilla et al., 2011). Considerando esta nueva posibilidad y comparando los valores de los astrágalos publicados por Scherer et al. (2009, tabla 1) de cf. Neolicaphrium recens Frenguelli, 1921, Eoauchenia primitiva y Diadiaphorus majusculus, el primero presenta valores apenas menores a los de E. primitiva pero marcadamente inferiores a los de D. majusculus, lo que es congruente con las medidas del húmero MPCN 1554 procedente de Uruguay.

\section{Diadiaphorus Ameghino, 1887b}

Especie tipo. Diadiaphorus majusculus Ameghino, 1887b.

Distribución geográfica y estratigráfica. Provincia de Santa Cruz, Formación Santa Cruz, ("subedad" Santacrucense tardía, Soria, 2001; Mioceno temprano). Barrancas del río Paraná, Provincia de Entre Ríos. "Mesopotamiense", base de la Formación Ituzaingó (Mioceno tardío).

Extended diagnosis. $P 2$ with two or three small labial cusps. P3-P4 with hypocone reduced. P3-M3 with labial side more developed than in Anisolophus and Tetramerorhinus, with parastyle and mesostyle developed, and metaconule closer to metacone. Anterolingual cingulum developed and upper molars with posterior fossette deeper than in Epitherium. Lingual cingulum extended to base of posterolingual groove. M3 with hypocone small, less lingual than Tetramerorhinus. Lower molars with entoconid very reduced; $m 3$ with hypoconulid without tending to form a third lobe, as Thoatherium. Skull similar to Tetramerorhinus cingulatum; nasals and premaxilla more reduced; postcranial skeleton more robust and larger than $\mathrm{T}$. cingulatum, similar to Anisolophus floweri, but slightly larger.

Diagnosis ampliada. P2 con dos o tres cúspides labiales pequeñas. P3-P4 con hipocono reducido. P3-M3 con el lado labial más desarrollado que en Anisolophus y Tetramerorhinus, con parastilo y mesostilo muy desarrollados y metacónulo próximo al metacono. Cíngulo anterolingual muy desarrollado y foseta posterior en los molares superiores más profunda que en Epitherium. Cíngulo lingual hasta la base del surco posterolingual. M3 con hipocono pequeño, menos lingual que en Tetramerorhinus. Molares inferiores con entocónido muy reducido; $\mathrm{m} 3$ con hipoconúlido sin tendencia a formar un tercer lóbulo, recordando a Thoatherium. Cráneo semejante al de Tetramerorhinus cingulatum; nasales y premaxilares más reducidos; esqueleto postcraneano más robusto y grande que el de Tetramerorhinus cingulatum, similar al de Anisolophus floweri, pero ligeramente más grande. 
Diadiaphorus eversus (Ameghino, 1891)

(Figura 5F; Apéndice 1; Tabla 1)

1891 Coelosoma eversa Ameghino, p. 137, fig. 9; 1904a, p. 485; Kraglievich, 1934, p. 41; Winge, 1942, p. 159; Mones, 1986, p. 138.

1898 Diadiaphorus eversus Ameghino, p. 167.

2001 Epitherium? eversus Soria, p. 95.

Distribución geográfica y estratigráfica. Barrancas del río Paraná, Entre Ríos. "Mesopotamiense", base de la Formación Ituzaingó (Mioceno tardío).

Holotipo. MACN A-5866, porción lingual de M1 o M2 izquierdo.

Material referido. Detallado en el Apéndice 1.

Extended diagnosis. Upper molar with posterior fossette deeper than in Epitherium laternarium, similar to Diadiaphorus majusculus. Posterolingual groove between protocone and hypocone more pronounced than E. laternarium. Anterolingual cingulum more robust than in D. majusculus, which confers a quadrangular outline. Lingual cingulum reaching the base of posterolingual groove as in Diadiaphorus.

Diagnosis ampliada. Molar superior con foseta posterior más profunda que en Epitherium laternarium, similar a Diadiaphorus majusculus. Surco posterolingual entre protocono e hipocono más pronunciado que en E. laternarium. Cíngulo anterolingual más robusto que en $D$. majusculus, lo que le confiere un contorno más cuadrangular. El cíngulo lingual alcanza la base del surco posterolingual como en Diadiaphorus.

Descripción. El fragmento de molar (Figura 5F) presenta un cíngulo muy desarrollado en la región anterolingual que alcanza la base del surco posterolingual. La foseta posterior es alargada bucolingualmente y profunda. El metacónulo es lofoide como en Epitherium laternarium. La pared posterior del hipocono (postcingulum) se curva hacia el ectolofo como en Diadiaphorus majusculus.

Discusión. Ameghino (1891) creó Coelosoma eversa dentro de la familia Mesorhinidae (= Macraucheniidae), asumiendo su parentesco con Mesorhinus Ameghino, 1885. Más tarde, Ameghino (1898) refirió dicha especie al proterotérido Diadiaphorus, la reivindicó posteriormente (Ameghino, 1904a) como Coelosoma eversa y volvió a citarla después como Diadiaphorus eversus (Ameghino, 1906). Posteriormente, Winge (1942) y Mones (1986) la refirieron nuevamente como C. eversa dentro de los Macraucheniidae y fue Soria (2001) quien la situó definitivamente en Proterotheriidae.

Delupi de Bianchini \& Bianchini (1971) plantearon excluir Coelosoma de los taxones mesopotamienses por estar basado en un molar incompleto que no pudieron hallar. Soria (2001) aclaró que el holotipo estaba ingresado en la colección del MACN como Diadiaphorus eversus (MACN A-5866) y que la estructura del molar era coherente con un Proterotheriidae avanzado, cercano a Epitherium laternarium, por lo que lo asignó tentativamente al género Epitherium.
MACNA-5866 presenta el cíngulo lingual más desarrollado que los molares de Epitherium laternarium (MACN A-210, MACN PV 8001) y Diadiaphorus majusculus (MLP 12305, MLP 12-306, MACN A-9198-99), principalmente en la región anterolingual. Al igual que en D. majusculus, alcanza la base del surco posterolingual. El surco posterolingual y la foseta posterior son más profundos que en E. laternarium, incluso con mayor desgaste, semejándose a D. majusculus. La morfología del metacónulo es lofoide, similar a Epitherium y diferente de D. majusculus, donde es bunoide. La forma y posición del hipocono difiere de la de $E$. laternarium, ya que la región lingual es roma y no está desplazado posterolabialmente, semejándose en este aspecto a D. majusculus. En general, las diferencias con Epitherium y sus semejanzas con Diadiaphorus permiten asignarlo a este último. Al mismo tiempo, el mayor desarrollo del cíngulo y la forma y posición del metacónulo lo separan de D. majusculus, por lo que se mantiene, con ciertas reservas, como Diadiaphorus eversus. Estos rasgos también diferencian a MACN A-5866 de las restantes especies "mesopotamienses": Brachytherium cuspidatum, Neobrachytherium ameghinoi y Proterotherium cervioides.

El fragmento de incisivo (MACN PV 13478), procedente del "Mesopotamiense", que Soria (2001) incluyó en Epitherium eversus es un ejemplar de tamaño general mayor que el correspondiente a Diadiaphorus majusculus. No obstante, sus dimensiones se correlacionan con las del fragmento de molar MACN A-5866, siendo demasiado grande para que pueda pertenecer a las demás especies "mesopotamienses". Por lo tanto, con las reservas del caso, se mantiene como Diadiaphorus eversus.

\section{ANÁLISIS FILOGENÉTICO}

Las relaciones filogenéticas de los Proterotheriidae fueron analizadas anteriormente por Kramarz \& Bond (2005) y Villafañe et al. (2012). En este trabajo, se toma como referencia la matriz de Villafañe et al. (2012) y se agregan cuatro taxones al grupo interno: Neobrachytherium morenoi, $N$. ullumense, $N$. ameghinoi y Diadiaphorus eversus y un carácter nuevo (21), que refleja la posición del entocónido en el m3 (Apéndice 3), resultando una matriz de datos con 20 taxones y 22 caracteres dentarios (Apéndice 4). Asimismo, se sustituye Lophogonodon paranensis por Brachytherium cuspidatum a partir de los resultados taxonómicos ya comentados y se agrega un estado más (2) en el carácter 6 (precíngulo en M1-M3) para reflejar la condición que presentan Diadiaphorus majusculus y D. eversus de alcanzar el surco lingual posterior.

Para la codificación del carácter 0 (nivel de hipsodoncia), se tuvieron en cuenta los trabajos de Cifelli \& Guerrero (1997), Bond et al. (2001) y Cassini et al. (2012). Para el cálculo del Índice de Hipsodoncia (IH) los tres trabajos se basaron en la metodología de Janis (1988). Bond et al. (2001) indican que los proterotéridos que habitaron la Patagonia durante el Oligoceno tardío-Mioceno medio y los registrados en Colombia tenían dientes braquiodontes y que 


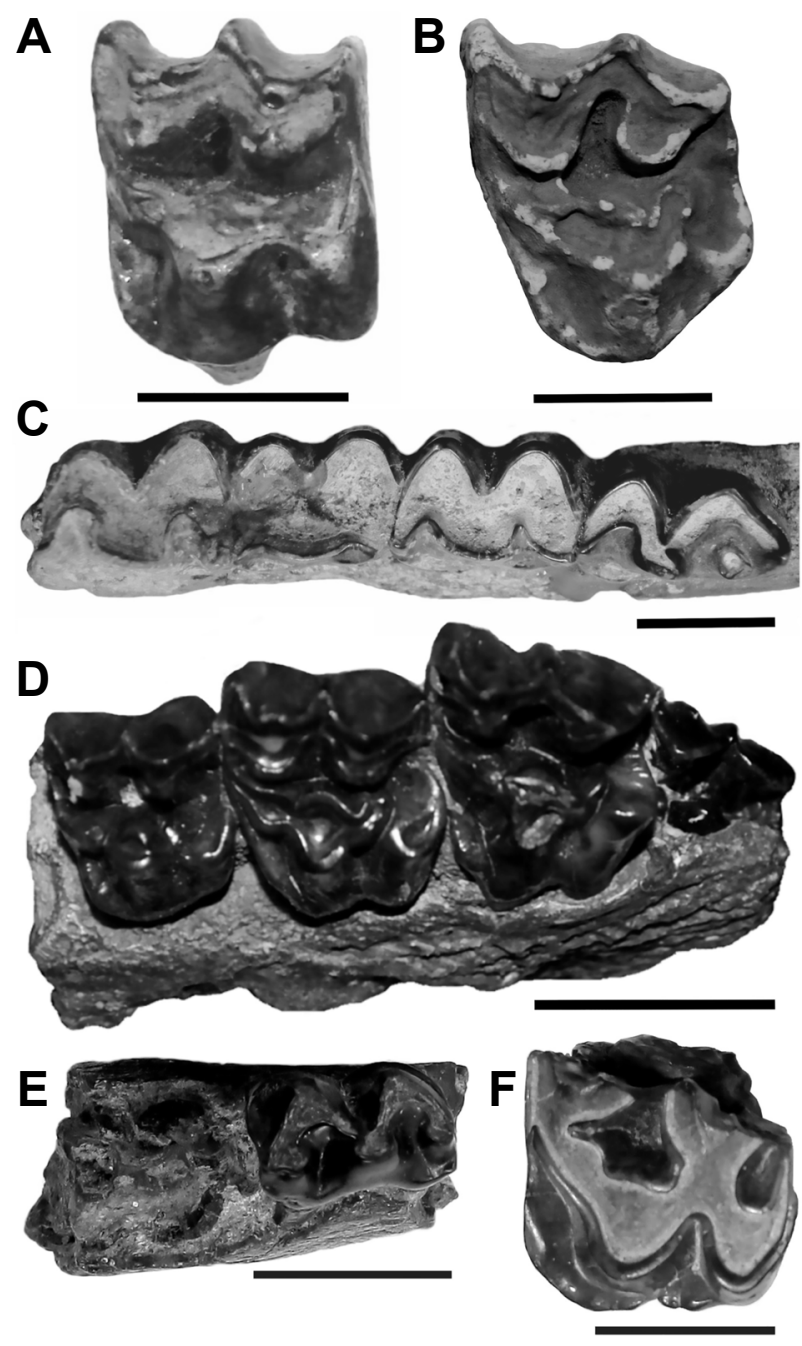

Figura 5. A-C, Neobrachytherium ameghinoi. A. MACN A-1401, M1 o M2 izquierdo (calco); B. MLP M-178, M3 izquierdo (calco); C. MACN PV 14308 (holotipo), fragmento mandibular derecho con p4m3. D-E, Proterotherium cervioides. D, MLP 69-XII-2-9 (holotipo), fragmento de maxilar izquierdo con P4-M2 y M3 en erupción; E, MACN PV 2631, dp4? izquierdo. F, Diadiaphorus eversus. MACN A-5866 (holotipo), fragmento de molar superior izquierdo. Todas en vista oclusal. Escalas $=1 \mathrm{~cm}$.

Figure 5. A-C, Neobrachytherium ameghinoi. A, MACN A-1401, left M1 or M2 (cast); B, MLP M-178, left M3 (cast); C, MACN PV 14308 (holotype), right mandibular fragment with p4-m3. D-E, Proterotherium cervioides. D, MLP 69-XII-2-9 (holotype), left maxillary fragment with P4-M2 and M3 erupting; E, MACN PV 2631, left dp4?. F, Diadiaphorus eversus. MACN A-5866 (holotype), left upper molar fragment. All in occlusal views. Scale bars $=1 \mathrm{~cm}$.

en Patagonia presentan IH con valores entre 0,83 y 1,16 . Desde el Mioceno tardío algunos proterotéridos muestran coronas más altas (1,62-1,75, mesodontes) y que en el caso de Neolicaphrium recens (Pleistoceno) los valores varían entre 2 y 2,5. Asimismo, las cifras publicadas por Cassini et al. (2012) para Thoatherium (0.94 \pm 0.21$)$, Anisolophus (0.78), Diadiaphorus $(1.33 \pm 0.06)$ y Tetramerorhinus (1.07 \pm 0.21 ), son bastante similares al rango publicado por Bond et al. (2001): 0,83-1,16 para los taxones de Patagonia, sólo Diadiaphorus caería por fuera del mismo, coincidiendo con lo apuntado por Cifelli \& Guerrero (1997) respecto de su mayor hipsodoncia.

En la codificación que se presenta aquí, Paranisolambda prodromus, Paramacrauchenia scamnata, Prolicaphrium specillatum, Lambdaconus lacerum, Picturotherium migueli y Proterotherium cervioides presentan un grado de hipsodoncia comparable al de las especies de Anisolophus (ver Soria, 2001) codificándose con estado 0 (lo que coincide con el valor más bajo calculado por Cassini et al., 2012). No obstante, en el caso de Thoatherium (1) y Tetramerorhinus (0) se debe considerar el desvío estándar dado que los valores están muy próximos $(0,94$ y 1,07$)$. Además, Soria (2001) sostiene que las especies de Tetramerorhinus presentan un grado de hipsodoncia mayor que las de Anisolophus, pero algo menor que Thoatherium y Diadiaphorus.

Por otro lado, cinco de los veinte taxones considerados en este trabajo no poseen $\mathrm{m} 3$ (Thoatheriopsis mendocensis, Proterotherium cervioides, Eoauchenia primitiva, Neobrachytherium morenoi y Diadiaphorus eversus), por lo que el índice de hipsodoncia no se puede calcular. No obstante, el carácter se codificó a partir de la comparación de otras piezas dentarias (superiores e inferiores) con las demás especies.

Finalmente, Bond et al. (2001) no indican cuáles fueron las especies del Mioceno tardío consideradas para el cálculo del IH y el valor publicado $(1,62-1,75)$ supera ampliamente el de los cuatro géneros santacrucenses. No obstante, el género Diadiaphorus (registrado en el Mioceno medio y tardío) con un índice de 1,33 es el que más se acerca, por lo tanto, dado que las especies de Neobrachytherium, Thoatheriopsis mendocensis y Brachytherium cuspidatum presentan un grado de hipsodoncia comparable a Diadiaphorus se las codificó con estado 1 , mientras que aquellas que tienen una corona visiblemente más alta (Epitherium laternarium, Eoauchenia primitiva y Diadiaphorus eversus) se codificaron con estado 2.

Respecto de la matriz de Villafañe et al. (2012), algunos caracteres han sufrido modificaciones en la codificación de los estados (Apéndice 4). En dicha matriz, Paranisolambda prodromus tiene estado no comparable (-) en los caracteres 15 (hipocono en el M3) y 17 (lóbulo distal en m3). Sin embargo, de acuerdo con Paula Couto (1952) y Cifelli (1983a), el carácter 15 se codifica como 0 y el 17 como 1. Para Epitherium laternarium, el carácter $17 \mathrm{se}$ ha podido codificar a partir de la localización del ejemplar MACN PV 8003, confirmando la presencia de lóbulo distal $\left(17^{\circ}\right)$. En esta misma especie, el carácter 20 (paracónido en m1-m2, aquí 19) se ha codificado como 1 (vestigial, unido al paralófido) a partir del estudio de dicho ejemplar. Asimismo, la revisión de los ejemplares MACN PV 2996, MLP 3492, MLP 3682 y FMNH P13190 de Thoatherium minusculum permitió comprobar que los pliegues del paracono y del metacono en premolares y molares pueden estar presentes como no, por lo que el carácter 1 se codifica como polimórfico $(\mathrm{C}=$ estado 1 , poco desarrollados y 2 , ausentes). Igualmente, para Neobrachytherium intermedium, se ha comprobado la existencia de dichos pliegues con poco desarrollo en distintos ejemplares: M1 de MACN PV 8429, M3 de MACN PV 8430, M1-M2 de MACN PV 8432, P4- 
M2 de PVL 3152 y P3-M3 de FMNH P14500, por lo que se codifica como 1, en lugar de ausente (2). Para este mismo taxón, la observación en detalle de FMNH P14500 reveló la existencia de un paracónido vestigial unido al paralófido en m1-m2, por lo que el carácter 19 se codifica con el estado 1 . En el caso de Diadiaphorus eversus, sólo se codificaron 4 de los 22 caracteres considerados $\left(0^{2}, 5^{2}, 6^{2}\right.$ y $\left.10^{1}\right)$.

La matriz fue analizada usando máxima parsimonia bajo pesos iguales e implicados con el programa TNT 1.1 (Goloboff et al., 2008). Los caracteres multiestado 0, 1, 3, 5 y 18 se mantuvieron ordenados como en Villafañe et al. (2012). Se realizó una búsqueda exacta (implicit enumeration) bajo pesos iguales que proporcionó 4 árboles más parsimoniosos de 65 pasos cada uno con un índice de consistencia (CI) de 0,54 y un índice de retención (RI) de 0,70 . En este trabajo se presenta tanto el consenso estricto resultante de dichos árboles (Figura 6) como el único que surge tras aplicar la técnica de pesos implicados $(\mathrm{K}=3)$. En este último caso, la topología obtenida (Figura 7) manifiesta una resolución mayor de las relaciones entre las especies.

El árbol de consenso estricto que resulta de la búsqueda bajo pesos iguales (Figura 6), muestra una politomía basal (nodo 1) donde aparecen prácticamente las mismas relaciones que en el árbol presentado por Villafañe et al. (2012), quienes comparten, incluso, las mismas sinapomorfías. Las diferencias se manifiestan a partir del nodo 5. Dentro de este gran clado, sustentado por el hipocono desarrollado en P4 (14') y el paracónido en m1-m2 vestigial, unido al paralófido $\left(19^{1}\right)$, la primera divergencia está representada por Tetramerorhinus lucarius. En el nodo 6, Brachytherium cuspidatum aparece como el grupo hermano de las especies restantes. Este nodo está apoyado por dentición mesodonta $\left(0^{1}\right), \mathrm{M} 1-\mathrm{M} 3$ con parastilo más desarrollado $\left(4^{2}\right)$ y precíngulo en M1-M3 sin unión al protocono $\left(6^{0}\right)$. El nodo 7 (sustentado por metacónulo en M1-M2 unido al hipocono, $9^{1}$, y metacónulo en M1-M2 poco desarrollado, $10^{\circ}$ ) reúne dos clados (Figura 6, nodos 8 y 11). Por un lado, se agrupan Epitherium laternarium y Eoauchenia primitiva, compartiendo dos sinapomorfías: dentición protohipsodonte y ausencia de pliegues labiales de paracono y metacono (nodo 11: $0^{2}, 1^{2}$ ). El otro clado (nodo 8, apoyado por estilos desarrollados, $3^{2}$, y ausencia de lóbulo distal en $\mathrm{m} 3,17^{1}$ ) está poco resuelto y muestra varias politomías. Las especies de Neobrachytherium de Catamarca $(N$. intermedium y $N$. morenoi) aparecen como grupo hermano del nodo 9 (sustentado por el metacónulo en M1M2 unido al protocono y entocónido en m3 libre o ausente: $\left.9^{0}, 21^{0,2}\right)$ que agrupa, a su vez, a las restantes especies de Neobrachytherium ( $N$. ameghinoi de Entre Ríos, N. ullumense registrada en San Juan y Buenos Aires) junto a Thoatherium minusculum. Otro clado (nodo 10) muestra una tricotomía con Diadiaphorus eversus, D. majusculus y Thoatheriopsis mendocensis, compartiendo dos sinapomorfías: precíngulo de M1-M2 unido al protocono $\left(6^{2}\right)$ y metacónulo desarrollado en M1-M2 $\left(10^{1}\right)$. Las relaciones entre estas tres especies no son claras, lo cual se deba probablemente a la cantidad de caracteres que no se pudieron codificar para $D$. eversus (sólo 4 de 22). La posición que presentan en esta hipótesis las especies de Neobrachytherium del Mioceno tardío de Catamarca ( $N$. intermedium y N. morenoi) apoya la posible separación genérica de las otras dos, como ya lo planteó Soria en su momento (Soria, 2001, p.151), aunque no lo concretó argumentando que las diferencias sutiles entre las especies de Noroeste de Argentina y la de Entre Ríos (N. ameghinoi) no eran suficientes para fundamentar la creación de un género nuevo. Dicha opinión es compartida en este trabajo y sustentada en la hipótesis filogenética presentada en la Figura 7, que apoya la monofilia del género Neobrachytherium.

En el árbol que se obtiene mediante la técnica de pesos implicados (Figura 7), las relaciones entre las especies basales están más resueltas y la posición de las especies entrerrianas y sus relaciones filogenéticas son ligeramente diferentes. La primera dicotomía separa a las especies de Anisolophus (nodo 2: $\left.4^{1}, 5^{1}\right)$ del resto de los taxones que, a su vez, se separan en dos grandes clados. En uno de ellos (nodo 4: 201), se separan sucesivamente Prolicaphrium specillatum, Proterotherium cervioides (nodo 5: $1^{0}, 8^{0}$ ), Picturotherium migueli (nodo 6: $5^{0}$ ) y el clado (Lambdaconus lacerum, Paramacrauchenia scamnata) (nodo 7: $13^{0}, 16^{\circ}$ ). El segundo gran clado presenta a Tetramerorhinus lucarius como grupo hermano del resto de los taxones reunidos en el nodo 9. En este se separa un primer grupo con Thoatherium minusculum y Diadaphorus majusculus, compartiendo tres sinapomorfías (nodo 10: $7^{1}, 17^{1}$ y $21^{2}$ ). En el segundo grupo, Brachytherium cuspidatum (nodo 11: $8^{0}$ ) permanece como grupo hermano de otros dos clados; uno de ellos agrupa en una politomía a Diadiaphorus eversus junto a las especies mio-pliocenas Epitherium laternarium y Eoauchenia primitiva, con una sola sinapomorfía, dentición

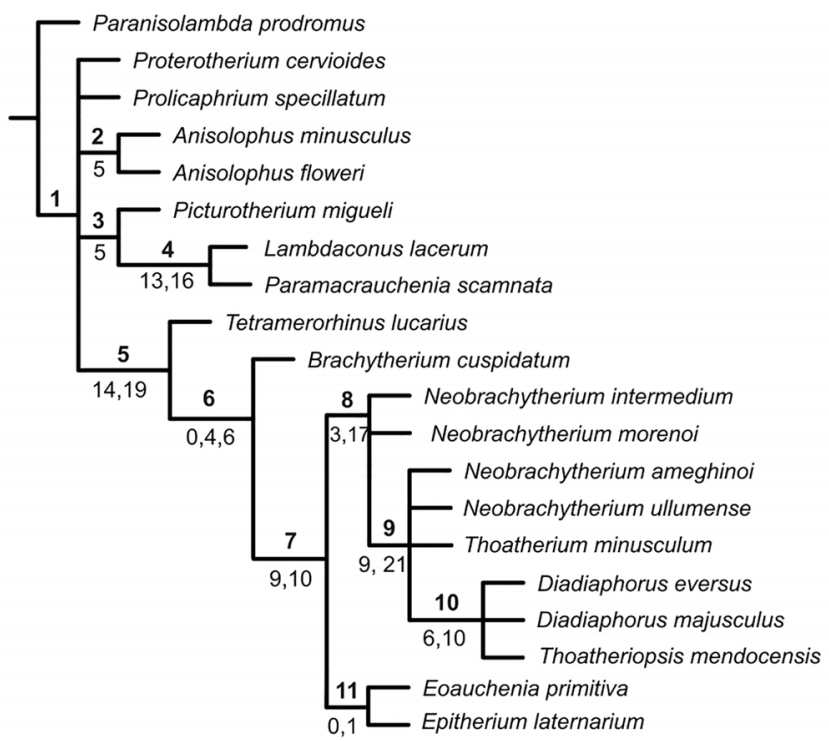

Figura 6. Árbol de consenso estricto del análisis cladístico de los Proterotheriidae que resulta tras una búsqueda exacta y pesos iguales. Los números sobre la rama indican los nodos. Los números debajo de la rama indican las sinapomorfías.

Figure 6. Strict consensus tree of the cladistics analysis of the Proterotheriidae which results from an exact search under equal weights. Numbers above branches indicate nodes and the below ones indicate synapomorphies. 


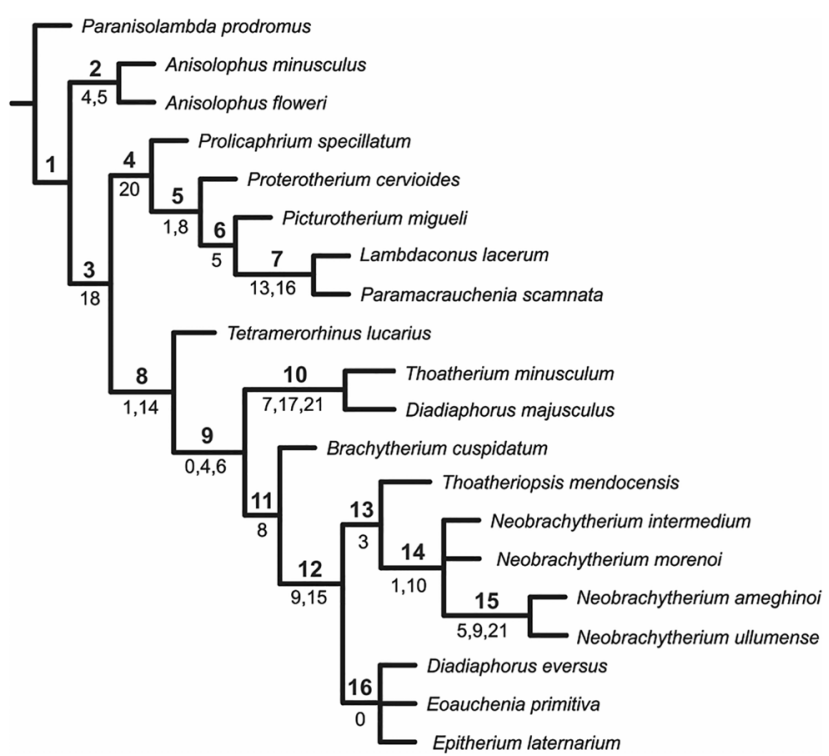

Figura 7. Árbol que resulta de la aplicación de la técnica de pesos implicados $(\mathrm{K}=3)$. Los números sobre la rama indican los nodos. Los números debajo de la rama indican las sinapomorfías.

Figure 7. Resultant tree by using implied weights $(K=3)$. Numbers above branches indicate nodes and the below ones, indicate synapomorphies.

protohipsodonte (nodo 16: $0^{2}$ ); el otro clado reúne a las especies del Mioceno tardío, con Thoatheriopsis mendocensis como grupo hermano de Neobrachytherium que, en este caso, sí aparece como un grupo monofilético con dos sinapomorfías (nodo 14: $1^{1}, 10^{\circ}$ ), quedando agrupadas las especies $N$. ameghinoi y $N$. ullumense mediante tres sinapomorfías (nodo 15: $5^{1}, 9^{2}, 21^{0}$ ).

Las hipótesis filogenéticas de los Proterotheriidae presentadas aquí, si bien mantienen un carácter preliminar dado que sólo se consideran caracteres dentarios, manifiestan coincidencias y ciertas discrepancias respecto del planteo evolutivo (pero no cladístico) y de ancestralidad elaborado por Soria (2001) para las especies mesopotámicas. Según este autor, Proterotherium cervioides es la especie más primitiva de la Formación Ituzaingó en función de su pequeño tamaño y de la retención de un patrón dentario bunoselenodonte, propio de las especies patagónicas del lapso OligocenoMioceno temprano. Dicha idea está corroborada en la hipótesis de la Figura 7, donde las relaciones de parentesco están resueltas mejor, dado que $P$. cervioides se ubica en una posición basal (en el análisis de la Figura 6 también aparece en la politomía basal), más emparentado con Picturotherium, Lambdaconus y Paramacrauchenia con quienes comparte, además, otro carácter primitivo como es la presencia de los pliegues labiales de paracono y metacono en los molariformes superiores. Brachytherium ("Lophogonodon" en Soria, 2001), si bien es considerado coetáneo de Thoatheriopsis y presenta afinidades con este género, aparece como grupo hermano de un gran clado que contiene a este último. Soria sostenía que, en función de su patrón más selenodonte y, en consecuencia, derivado respecto a Brachytherium, Thoatheriopsis debía haberse originado de una especie más primitiva que la de B. cuspidatum y no necesariamente perteneciente a este género. Esta idea no se contradice con lo que se puede observar en la hipótesis de la Figura 7, en virtud de la posición que adoptan sendos taxones. Además, Brachytherium presenta ejemplares con pliegues labiales y estilos menos desarrollados en los molariformes superiores, caracteres plesiomórficos respecto a Thoatheriopsis. Respecto a Neobrachytherium ameghinoi, Soria (2001, p. 151) hipotetizó que pudo tener un origen común con $N$. ullumense dado que comparten el entocónido libre en $\mathrm{m} 3$. También indicó que $N$. ullumense presentaba caracteres propios como la cercanía del paracónido al metacónido en m1-m3 y que la estructura del trigónido de estas piezas podía ser derivada de una presente en $N$. ameghinoi. En consecuencia, la especie ancestral debía poseer las características de $N$. ameghinoi, pero ser de tamaño menor. En este trabajo, estas especies aparecen más emparentadas por el carácter indicado por Soria (2001), pero además por compartir la unión del protocono al hipocono y la posición del metacónulo en M1-M2. En cuanto a Diadiaphorus eversus, Soria (2001) consideró que presentaba más afinidades con Epitherium por su grado de hipsodoncia (mayor que en las otras especies de Entre Ríos), relación que no es apoyada claramente por los resultados obtenidos con pesos implicados (Figura 7, politomía del nodo 16) y tampoco en el análisis reflejado en la figura 6 , donde ambos taxones aparecen en clados diferentes. Sin dudas, el hallazgo de nuevo material permitirá cotejar los resultados actuales. Por el momento, en virtud de las dos sinapomorfías que lo reúnen junto a Diadiaphorus majusculus y Thoatheriopsis mendocensis y de las características morfológicas mencionadas en el apartado correspondiente, se lo mantiene como D. eversus.

\section{CONCLUSIONES}

El estudio de ejemplares dentarios (publicados e inéditos) de proterotéridos procedentes del "Mesopotamiense" de Entre Ríos ha permitido considerar como válidas las siguientes especies: Brachytherium cuspidatum, Neobrachytherium ameghinoi, Proterotherium cervioides y Diadiaphorus eversus. Se valida el nombre Brachytherium cuspidatum, antes considerado nomen dubium por Soria (2001). Asimismo, las diferencias de tamaño - pero no morfológicas - entre Lophogonodon paranensis y L. gradatum son interpretadas como un dimorfismo sexual intraespecífico, conclusión que se ve apoyada por análisis discriminantes, siendo sendos taxones sinónimos entre sí y de $B$. cuspidatum. La comparación del material entrerriano con el de otras regiones permitió establecer nuevas características y ampliar las diagnosis de todas las especies reconocidas.

Las relaciones filogenéticas de los proterotéridos entrerrianos se establecieron a través de un análisis cladístico basado en análisis previos (Kramarz \& Bond, 2005; Villafañe et al., 2012). La nueva matriz incluyó cuatro especies más que el análisis de Villafañe et al. (2012), se modificó la codificación de ciertos caracteres, se agregó un estado al carácter 6 (2) y se incorporó uno nuevo (21). En las hipótesis 
filogenéticas presentadas (Figuras 6-7), Proterotherium cervioides ocupa una posición basal junto a especies santacrucenses y colloncurenses, Brachytherium cuspidatum aparece relacionado a Tetramerorhinus lucarius (Figura 6) y como grupo hermano de taxones del Mioceno temprano y tardío y del Plioceno temprano (Figuras 6-7). Diadiaphorus eversus forma un clado con D. majusculus y Thoatheriopsis mendocensis (Figura 6) o con Eoauchenia y Epitherium (Figura 7), en ambos casos sus relaciones no están claramente establecidas. Neobrachytherium constituye un grupo parafilético en la topología de la Figura 6, pero su monofilia está sustentada en la de la Figura 7; en ambos árboles, $N$. ameghinoi está más emparentado con $N$. ullumense.

\section{AGRADECIMIENTOS}

A los revisores y editores cuyas sugerencias enriquecieron este trabajo. A M. Reguero (MLP), A. Kramarz y S. M. Álvarez (MACN), J. Peña y G. Ibargoyen (MAS PALEOVERT) por facilitarme el estudio de las colecciones a su cargo. A E. Cerdeño, J. Noriega y A. Kramarz que mejoraron sustancialmente la versión preliminar de este manuscrito. A B. Ferrero que colaboró con los análisis filogenéticos y estadísticos y a N. Núñez Otaño que realizó los esquemas dentarios. Este trabajo fue financiado por el Consejo Nacional de Investigaciones Científicas y Técnicas (CONICET) (PIP-CONICET 886) y la Agencia Nacional de Promoción Científica y Tecnológica (PICT-ANPCYT 392).

\section{REFERENCIAS}

Aceñolaza, F.G. 1976. Consideraciones bioestratigráficas sobre el Terciario marino de Paraná y alrededores. Acta Geológica Lilloana, 13:91-108.

Ameghino, F. 1883a. Sobre una colección de mamíferos fósiles recogidos por el profesor Pedro Scalabrini en las barrancas del río Paraná. Boletín de la Academia Nacional de Ciencias de Córdoba, 5:101-116.

Ameghino, F. 1883b. Sobre una nueva colección de mamíferos fósiles recogidos por el profesor Pedro Scalabrini en las barrancas del Paraná. Boletín de la Academia Nacional de Ciencias de Córdoba, 5:257-306.

Ameghino, F. 1885. Nuevos restos de mamíferos fósiles oligocenos recogidos por el Profesor Pedro Scalabrini y pertenecientes al Museo Provincial de la ciudad de Paraná. Boletín de la Academia Nacional de Ciencias de Córdoba, 8:1-207.

Ameghino, F. 1886. Contribuciones al conocimiento de los mamíferos fósiles de los terrenos terciarios antiguos del Paraná. Boletín de la Academia Nacional de Ciencias de Córdoba, 9:5-228.

Ameghino, F. 1887a. Apuntes preliminares sobre algunos mamíferos extinguidos del yacimiento de Monte Hermoso existentes en el Museo de La Plata. Obras completas y correspondencia científica. Paraná y Monte Hermoso, 5:337-354.

Ameghino, F. 1887b. Enumeración sistemática de las especies de mamíferos fósiles coleccionados por Carlos Ameghino en los terrenos eocenos de la Patagonia austral y depositados en el Museo de La Plata. Obras completas y correspondencia científica. Paraná y Monte Hermoso, 5:445-468.
Ameghino, F. 1888. Lista de las especies de mamíferos fósiles del mioceno superior de Monte Hermoso hasta ahora conocidas. Obras completas y correspondencia cientifica. Paraná y Monte Hermoso, 5:481-496.

Ameghino, F. 1889. Contribución al conocimiento de los mamíferos fósiles de la República Argentina. Obras completas y correspondencia cientifica, 6:1-1027.

Ameghino, F. 1891. Caracteres diagnósticos de cincuenta especies nuevas de mamíferos fósiles argentinos. Obras completas y correspondencia cientifica, 10:157-201.

Ameghino, F. 1894. Enumération synoptique des espèces de mammifères fossiles des formations éocènes de Patagonie. Boletín de la Academia Nacional de Ciencias de Córdoba, 13:259-452.

Ameghino, F. 1898. Sinopsis geológico-paleontológica. Segundo censo de la República Argentina, 1:111-255.

Ameghino, F. 1904a. Recherches de morphologie phylogénétique sur les molaires supérieures des ongulés. Anales del Museo Nacional de Buenos Aires, 9:1-541.

Ameghino, F. 1904b. Nuevas especies de mamíferos cretáceos y terciarios de la República Argentina. Anales de la Sociedad Cientifica Argentina de Buenos Aires, 57:162-175.

Ameghino, F. 1906. Les Formations Sedimentaires du Crétacé Supérieur et du Tertiaire de Patagonie avec un paralléle entre leurs faunes mammalogiques et celles de l'ancien continent. Anales del Museo Nacional de Buenos Aires, 15:1-568.

Andrés, M.; Alcalde, G.M.; Azanza, B.; Morales, J. \& Alberdi, M.T. 2008. Sex-specific differences of the skeleton in North African gazelles (Mammalia, Artiodactyla, Bovidae). In: INTERNATIONAL CONGRESS OF ZOOLOGY, 20, 2008. Abstracts, Paris, ISZS \& SZF, p. 31R.

Azanza, B.; De Miguel, D. \& Andrés, M. 2011. Dimorfismo sexual, crecimiento y ciclo de los apéndices craneales en el ciervo mioceno Dicrocerus elegans (Artiodactyla, Cervidae). In: JORNADAS DE LA SOCIEDAD ESPAÑOLA DE PALEONTOLOGÍA, 27, 2011. Libro de Resúmenes, Sabadell, SEP, p. 39-42.

Bergqvist, L.P. 2008. Postcranial Skeleton of the Upper Paleocene (Itaboraian) "Condylarthra" (Mammalia) of Itaboraí Basin, Brazil. In: E.J Sargis \& M. Dagosto (eds.) Mammalian evolutionary morphology: a tribute to Frederick S. Szalay, Springer, p.107-133. doi:10.1007/978-1-4020-6997-0_6

Bond, M.; Cerdeño, E. \& López, G. 1995. Los ungulados nativos de América del Sur. In: M.T. Alberdi; G. Leone \& E.O. Tonni (eds.) Evolución biológica y climática de la región pampeana durante los últimos cinco millones de años. Un ensayo de correlación con el Mediterráneo occidental, Madrid, Museo Nacional de Ciencias Naturales, Consejo Superior de Investigaciones Científicas, p. 257-276 (Monografías 12).

Bond, M.; Perea, D.; Ubilla, M. \& Tauber, A. 2001. Neolicaphrium recens Frenguelli, 1921, the only surviving Proterotheriidae (Litopterna, Mammalia) into the South American Pleistocene. Palaeovertebrata, 30:37-50.

Bond, M.; Reguero, M.A.; Vizcaíno, S.F. \& Marenssi, S.A. 2006. A new 'South American ungulate' (Mammalia: Litopterna) from the Eocene of the Antarctic Peninsula. In: J.E. Francis; D. Pirrie \& J.A. Crame (eds.) Cretaceous-Tertiary high-latitude palaeoenvironments, James Ross Basin, Antarctica, Geological Society, p. 163-176 (Special Publication 258). doi:10.1144/GSL. SP.2006.258.01.12

Brandoni, D. 2005. Los Megatheriinae (Xenarthra, Tardigrada) de la Formación Ituzaingó (Mioceno Superior-Plioceno) de la provincia de Entre Ríos. In: Temas de la Biodiversidad Fluvial 
del Litoral II, San Miguel de Tucumán, Instituto Superior de Correlación Geológica, p. 27-35 (Miscelánea 14).

Brandoni, D. 2009. Descripción del fémur de Protomegalonyx chasicoensis Scillato-Yané (Mammalia, Xenarthra, Megalonychidae) de la Formación Arroyo Chasicó (Mioceno tardío), provincia de Buenos Aires, Argentina. Consideraciones sistemáticas sobre los perezosos de Edad Chasiquense. Ameghiniana, 46:513-521.

Brandoni, D. 2011. The Megalonychidae (Xenarthra, Tardigrada) from the late Miocene of Entre Ríos Province, Argentina, with remarks on their systematics and biogeography. Geobios, 44:3344. doi:10.1016/j.geobios.2010.06.005

Brandoni, D. 2013. Los Tardigrada (Mammalia, Xenarthra) del Mioceno tardío de Entre Ríos, Argentina. In: D. Brandoni \& J.I. Noriega (eds.) El Neógeno de la Mesopotamia argentina, Buenos Aires, Asociación Paleontológica Argentina, p. 135-144 (Publicación Especial 14).

Brandoni, D.; Schmidt, G.I.; Candela, A.M.; Noriega, J.I.; Brunetto, E. \& Fiorelli, L.E. 2012. Mammals from the Salicas Formation (Late Miocene), La Rioja Province, Northwestern Argentina. Ameghiniana, 49:375-387. doi:10.5710/AMGH.v49i3(467)

Bravard, A. 1858. Monografia de los terrenos marinos terciarios de las cercanías del Paraná. Buenos Aires, Imprenta de Pablo e Coni, $107 \mathrm{p}$.

Brunetto, E.; Noriega, J.I. \& Brandoni, D. 2013. Sedimentología, estratigrafía y edad de la Formación Ituzaingó en la provincia de Entre Ríos, Argentina. In: D. Brandoni \& J.I. Noriega (eds.) El Neógeno de la Mesopotamia argentina, Asociación Paleontológica Argentina, p. 13-27 (Publicación Especial 14).

Buckley, M. 2015. Ancient collagen reveals evolutionary history of the endemic South American 'ungulates'. Proceedings of the Royal Society B, 282:20142671. doi:10.1098/rspb.2014.2671

Burmeister, G. 1885. Examen crítico de los mamíferos y reptiles fósiles denominados por Don Augusto Bravard. Anales Museo Nacional de Buenos Aires, 3:95-173.

Burmeister, G. 1891. Continuación a las adiciones al examen crítico de los mamíferos fósiles terciarios. Anales del Museo Nacional de Buenos Aires, 3:401-461.

Cabrera, A. 1939. Sobre vertebrados fósiles del Plioceno de Adolfo Alsina. Revista del Museo de La Plata, 2:3-35.

Candela, A.M.; Bonini, R.A. \& Noriega, J.I. 2012. First continental vertebrates from the marine Paraná Formation (Late Miocene, Mesopotamia, Argentina): chronology, biogeography, and paleoenvironments. Geobios, 45:515-526. doi:10.1016/j. geobios.2012.05.003

Cassini, G.H.; Cerdeño, E.; Villafañe, A.L. \& Muñoz, N.A. 2012. Paleobiology of Santacrucian native ungulates (Meridiungulata: Astrapotheria, Litopterna, and Notoungulata). In: S.F. Vizcaíno; R.F. Kay \& M.S. Bargo (eds.) Early Miocene Paleobiology in Patagonia: high-latitude paleocommunities of the Santa Cruz Formation, Cambridge University Press, p. 243-286.

Cerdeño, E. 2003. Neobrachytherium ullumense (Proterotheriidae, Litopterna) en el Mioceno Superior de la Provincia de Buenos Aires (Argentina). Ameghiniana, 40:505-508.

Cifelli, R.L. 1983a. The Origin and affinities of the South American Condylarthra and Early Tertiary Litopterna (Mammalia). American Museum Novitates, 2772:1-49.

Cifelli, R.L. 1983b. Eutherian tarsals from the late Paleocene of Brazil. American Museum Novitates, 2761:1-31.

Cifelli, R.L. \& Guerrero, J. 1997. Litopterns. In: R. Kay; R.H. Madden; R.L. Cifelli \& J.J. Flynn (eds.) Vertebrate paleontology in the neotropics: the Miocene fauna of La Venta, Colombia,
Smithsonian Institution Press, p. 289-302.

Cione, A.L. et al. 2000. Miocene vertebrates from Entre Ríos Province, eastern Argentina. In: F.G. Aceñolaza \& R. Herbst (eds.) El Neógeno de Argentina, Instituto Superior de Correlación Geológica, p. 191-237. (Correlación Geológica 14).

Cozzuol, M.A. 2006. The Acre vertebrate fauna: age, diversity, and geography. Journal of South American Earth Sciences, 21:185203. doi:10.1016/j.jsames.2006.03.005

Delupi Bianchini, L.H. \& Bianchini, J.J. 1971. Revisión de los Proterotheriinae (Mammalia, Litopterna) del Mesopotamiense. Ameghiniana, 8:1-24.

Deng, T. 2005. New discovery of Iranotherium morgani (Perissodactyla, Rhinocerotidae) from the late Miocene of the Linxia basin in Gansu, China, and its sexual dimorphism. Journal of Vertebrate Paleontology, 25:442-450. doi:10.1671/02724634(2005)025[0442:NDOIMP]2.0.CO;2

Frenguelli, J. 1920. Apuntes sobre mamíferos fósiles entrerrianos. Boletín de la Academia Nacional de Ciencias de Córdoba, 24:27-54.

Frenguelli, J. 1921. Sobre un proterotérido del Pampeano superior de Córdoba, Neolicaphrium recens, nov. Actas de la Academia Nacional de Ciencias de Córdoba, 7:7-23.

Gervais, P. 1855. Recherches sur les mammifères fossiles de l'Amérique méridionale. Comptes Rendus de l'Académie des Sciences, 40:1112-1114.

Góis, F.; Scillato-Yané, G.J.; Carlini, A.A. \& Guilherme, E. 2013. A new species of Scirrotherium Edmund \& Theodor, 1997 (Xenarthra, Cingulata, Pampatheriidae) from the late Miocene of South America. Alcheringa, 37:175-186. doi:10.1080/0311 5518.2013.733510

Goloboff, P.; Farris, J. \& Nixon, K. 2008. TNT, a free program for phylogenetic analysis. Cladistics, 24:774-786. doi: 10.1111/j.1096-0031.2008.00217.x

InfoStat, 2002. InfoStat, versión 1.1. Manual del Usuario. $1^{\text {st }}$ ed. Universidad Nacional de Córdoba, Grupo InfoStat, FCA, Editorial Brujas.

Kraglievich, L. 1930. Hallazgo de un proterotérido en la República del Uruguay (Proterotherium berroi, n. sp.). Revista de la Sociedad Amigos de la Arqueología, 4:197-203.

Kraglievich, L. 1931. Cuatro notas paleontológicas sobre Octomylodon aversus Ameghino, Argyrolagus palmeri Ameghino, Tetrastylus montanus Ameghino y Muñizia paranensis n. gen., n. sp. Physis, 10:242-266.

Kraglievich, L. 1934. La antigüedad pliocena de las faunas de Monte Hermoso y Chapadmalal, deducidas de su comparación con las que le precedieron y sucedieron. Montevideo, El Siglo Ilustrado, $136 \mathrm{p}$.

Kramarz, A.G. \& Bond, M. 2005. Los Litopterna (Mammalia) de la Formación Pinturas, Mioceno Temprano-Medio de Patagonia. Ameghiniana, 42:611-625.

Kurtén, B. 1969. Sexual dimorphism in fossil mammals. International Union of Geological Sciences, 1:226-233.

Janis, C.M. 1988. An estimation of tooth volume and hypsodonty indices in Ungulate Mammals, and the correlation of these factors with dietary preferences. In: INTERNATIONAL SYMPOSIUM ON DENTAL MORPHOLOGY, 7, 1986. Proceedings, Paris, p. 367-387.

Loison, A.; Gaillard, J.; Pélabon, C. \& Yoccoz, N.G. 1999. What factors shape sexual size dimorphism in ungulates? Evolutionary Ecology Research, 1:611-633.

McDonald, H.G. 2006. Sexual dimorphism in the skull of Harlan's Ground Sloth. Los Angeles, Natural History Museum of Los Angeles County, p. 1-9 (Contributions in Science 510). 
Mead, A.J. 2000. Sexual dimorphism and paleoecology in Teleoceras, a North American Miocene rhinoceros. Paleobiology, 26:689-706. doi:10.1666/0094-8373(2000)026<0689:SDAPIT>2.0.CO;2

Mones, A. 1986. Paleovertebrata Sudamericana. Catálogo sistemático de los Vertebrados fósiles de América del Sur. Parte I. Lista preliminar y Bibliografía. Courier Forschunginstitut Senckenberg, 82:1-625.

Montenegro, F.; Roland, G.; García, G.; Rinderknecht, A.; Ubilla, D.; Lecuona, G. \& Jones, W. 2011. Los vertebrados fósiles del Arroyo Perico Flaco, Pleistoceno-Holoceno del Departamento de Soriano, Uruguay. Ameghiniana, 48:184.

Moreno, F.P. \& Mercerat A. 1891. Exploración arqueológica en la provincia de Catamarca: Paleontología. Revista del Museo de La Plata, 1:222-236.

Pascual, R. 1970. Evolución de comunidades, cambios faunísticos e integraciones biocenóticas de los vertebrados cenozoicos de Argentina. In: CONGRESO LATINO AMERICANO DE ZOOLOGÍA, 4, 1970. Actas, Caracas, p. 991-1088.

Pascual, R.; Ortega Hinojosa, E.; Gondar, D. \& Tonni, E.P. 1966. Las edades del Cenozoico mamalífero de la provincia de Buenos Aires. In: A.V. Borrello (ed.) Paleontografía Bonaerense. Vertebrata, p. 1-202.

Pascual, R. \& Odreman Rivas, O.E. 1971. Evolución de las comunidades de vertebrados del terciario argentino. Los aspectos zoogeográficos relacionados. Ameghiniana, 7:372-412.

Paula Couto, C. 1952. Fossil mammals from the beginning of the Cenozoic in Brazil. Condylarthra, Litopterna, Xenungulata, and Astrapotheria. Bulletin of the American Museum of Natural History, 99:355-394.

Rovereto, C. 1914. Los estratos araucanos y sus fósiles. Anales del Museo Nacional de Historia Natural de Buenos Aires, 25:1-250.

Sánchez, I.M.; Quiralte, V.; Morales, J. \& Azanza, B. 2010. Sexual dimorphism of the frontal appendages of the early Miocene African pecoran Prolibytherium Arambourg, 1961 (Mammalia, Ruminantia). Journal of Vertebrate Paleontology, 30:1306-1310. doi:10.2307/40864406

Scherer, C.S.; Pitana, V.G. \& Ribeiro, A.M. 2009. Proterotheriidae and Macraucheniidae (Litopterna, Mammalia) from the Pleistocene of Rio Grande do Sul State, Brazil. Revista Brasileira de Paleontologia, 12:231-246. doi:10.4072/rbp.2009.3.06

Schmidt, G.I. 2011. Los Proterotheriidae (Litopterna) de Entre Ríos: consideraciones nomenclaturales e implicancias sistemáticas. Ameghiniana, 48:405-408. doi:10.5710/AMGH.v48i2(291)

Schmidt, G.I. 2013. Litopterna y Notoungulata (Mammalia) de la Formación Ituzaingó (Mioceno tardio) de la provincia de Entre Ríos: sistemática, bioestratigrafia y paleobiogeografia. Facultad de Ciencias Naturales y Museo, Universidad Nacional de La Plata, Tesis Doctoral, 423 p.
Scott, W.B. 1910. Mammalia of the Santa Cruz beds. Part 1: Litopterna. Reports of the Princeton University Expedition to Patagonia (1896-1899), 7:1-156.

Short, R.V. \& Balaban, E. 1994. The differences between the sexes. Cambridge, Cambridge University Press, 400 p.

Soria, M.F. 1981. Los Litopterna del Colhuehuapense (Oligoceno Tardío) de la Argentina. Revista del Museo Argentino de Ciencias Naturales "Bernardino Rivadavia”, Serie Paleontología, 3:1-54.

Soria, M.F. 1989. Notopterna: un nuevo orden de mamíferos ungulados eógenos de América de Sur. Parte II. Notonychops powelli gen. et sp. nov. (Notonychopidae nov.) de la Formación Río Loro (Paleoceno medio), provincia de Tucumán, Argentina. Ameghiniana, 25:259-272.

Soria, M.F. 2001. Los Proterotheriidae (Litopterna, Mammalia), sistemática, origen y filogenia. Monografías del Museo Argentino de Ciencias Naturales, 1:1-167.

Ubilla, M.; Perea, D.; Bond, M. \& Rinderknecht, A. 2011. The first cranial remains of the Pleistocene proterotheriid Neolicaphrium recens Frenguelli, 1921 (Mammalia, Litopterna): a comparative approach. Journal of Vertebrate Paleontology, 31:193-201. doi:10.1080/02724634.2011.539647

Villafañe, A.L.; Ortiz-Jaureguizar, E. \& Bond, M. 2006. Cambios en la riqueza taxonómica y en las tasas de primera y última aparición de los Proterotheriidae (Mammalia, Litopterna) durante el Cenozoico. Estudios Geológicos, 62:155-166.

Villafañe, A.L.; Schmidt, G.I. \& Cerdeño. E. 2012. Consideraciones sistemáticas y bioestratigráficas acerca de Thoatheriopsis mendocensis Soria, 2001 (Litopterna, Proterotheriidae). Ameghiniana, 49:365-374. doi:10.5710/AMGH.v49i3(480)

Vucetich, M.G. et al. 2007. Mamíferos continentales del Paleógeno argentino: las investigaciones de los últimos cincuenta años. In S. Archangelsky; T. Sánchez \& E.P. Tonni (eds.) Ameghiniana, $50^{\text {th }}$ aniversario, Asociación Paleontológica Argentina, p. 239255 (Publicación Especial 11).

Welker, F. et al. 2015. Ancient proteins resolve the evolutionary history of Darwin's South American ungulates. Nature, 522:8184. doi:10.1038/nature14249

Winge, H. 1942. The interrelationships of the mammalian genera: Ungulata, Cetacea. In: A.D.S. Jenson; R. Sparck \& H. Voesoe (eds.) The interrelationships of the mammalian genera, Reitzels Forlag, $308 \mathrm{p}$.

Received in April, 2015; accepted in August, 2015. 
Apéndice 1. Listado de los ejemplares, por taxón, estudiados en este trabajo. Abreviaturas institucionales: en Material y Métodos.

Appendix 1. List of specimens by taxon studied in this work. Institutional abreviations: in Material and Methods.

\section{Brachytherium cuspidatum}

MACN A-5865 (holotipo de Proterotherium gradatum), porción de maxilar izquierdo con parte posterior del P1 y P2-P3 completos; MACN A-11000a (holotipo de Lophogonodon paranensis), DP4 izquierdo aislado; MLP 81-XI-29-8, fragmento de maxilar derecho con DP1-DP4; MACN A-5864, M1 o M2 izquierdo aislado; MACN PV 13189, M1 o M2 derecho desgastado; MACN PV 9250, M3 derecho aislado; MACN PV 14303, porción de maxilar derecho con M2-M3; MACN PV 16009, M1 derecho, M2 (2) izquierdos, M3 derecho e izquierdo; MLP 69-XII-2-11, P3-M1 derechos; FCP-V-M-053, fragmento de maxilar izquierdo con P4-M2; MLP 69-XII-2-4 (holotipo), fragmento mandibular derecho con dp2-dp4 y m1 en erupción; MLP 70-I-10-3 (holotipo de Licaphrium mesopotamiense), fragmento mandibular izquierdo con $\mathrm{p} 3-\mathrm{m} 3$; MACN PV 4001, fragmento de rama mandibular izquierda con p4-m3; MACN PV 4435, fragmento de rama mandibular izquierda con p4-m3; MLP 12-103a, fragmento de rama mandibular izquierda con p3-m1; MACN PV 13172, fragmento mandibular izquierdo con dp3, dp4 y alvéolo de m1; MACN PV 13173, fragmento mandibular derecho con p3-m2; MACN PV 4433, m1 o m2 izquierdo; MACN PV 9155, dp4 izquierdo; MACN PV 9156, dp4 derecho; MAS PALEO-VERT 400, fragmento mandibular derecho con dp4; MAS PALEOVERT 401, dp4 derecho; MACN PV 13187, fragmento de rama mandibular derecha con p3-p4; MAS PALEO-VERT 402, fragmento mandibular derecho con p3-m3; MLP 69-XII-2-3 (calcos MACN 4417, MACN A-1465, MLP M-175), fragmento de rama mandibular izquierda con p3-m2; MLP 69-XII-2-6 (calcos MLP M-176 y MACN A-1572), molar inferior m1 o m2 izquierdo aislado; MLP 12-110a, porción rama mandibular derecha con dp3-m1; MLP 121483, fragmento de rama mandibular izquierda con p2-m3; MLP 41-XII-13-345, fragmento de rama mandibular derecha con m2-m3; MLP 41-XII-13-348, fragmento de rama mandibular izquierda con p3-m1 y raíz del p2; MLP 52-X-1-72, fragmento de rama mandibular izquierda con p4-m3; MACN PV 1208, fragmento de rama mandibular derecha con talónido de dp3 y dp4 completo; MACN PV 3962, rama mandibular derecha con parte de la rama ascendente, parte de $\mathrm{p} 2$ y p3-m3 completos, muy desgastados; MACN PV 4058, fragmento de rama mandibular izquierda con parte de la sínfisis y p3-m1; MACN PV 4404, porción mandibular izquierda con m1-m2; MACN PV 4677, fragmento de rama mandibular izquierda con p1-p4; MACN PV 4717, fragmento de rama mandibular derecha con p3-m2; MACN PV 4750, fragmento mandibular izquierdo con m2-m3; MACN PV 14302, fragmento de rama mandibular izquierda con $\mathrm{m} 3$ y parte de la rama ascendente; MACN PV 13171, fragmento de rama mandibular derecha con p4-m2; MACN PV 9249, p4 derecho aislado; CICYTTP PV-M-1-925, fragmento mandibular derecho con m2; MLP 81-XI-29-2, porción mandibular derecha con p3, alvéolos de p2 y p1; MACN PV 3177, fragmento mandibular izquierdo con p4-m1; MACN PV 4747, fragmento mandibular derecho con p3; MACN PV 16009, m1 o m2 derecho aislado; MACN PV 4121, fragmento mandibular derecho con $\mathrm{m} 1$ (roto) - $\mathrm{m} 3$ muy desgastados; MACN PV 14305, fragmento mandibular derecho con p3-p4; MACN PV 14306, fragmento mandibular izquierdo con p3-m1; MACN PV 9141, fragmento mandibular derecho con parte de m1 y m2-m3; MACN PV 4009, fragmento mandibular derecho con $\mathrm{m} 2 \mathrm{y} \mathrm{m} 3$.

\section{Neobrachytherium ameghinoi}

Calco MLP M-177 (y MACN-A 1401-03), M1 o M2 izquierdo aislado; calco MLP M-178, M3 aislado; MACN PV 9150, M1 o M2 derecho aislado; MACN PV 13212, M1 o M2 izquierdo aislado; MACN PV 14308 (holotipo), fragmento mandibular derecho con p4-m3; MACN PV 2619, fragmento de rama mandibular izquierda con m3; MACN PV 3998 y 3999, m3 y m2 izquierdos aislados, posiblemente del mismo individuo; MACN PV 13164, fragmento mandibular izquierdo con m3; MACN PV 4748, fragmento mandibular izquierdo con m1-m3; MLP 12-102a, fragmento mandibular izquierdo con p4-m3; MLP 69-XII-2-5, fragmento mandibular izquierdo con talónido del p4, m1-m2; MLP 37-III-10-2, fragmento de rama mandibular izquierda con m2-m3.

\section{Neobrachytherium morenoi}

MACN PV 8428 (holotipo) cráneo incompleto con restos de P2, P4-M2 izquierdos y M1-M2 derechos; MACN PV 8435, P4 derecho sin la región labial; MACN PV 8431 (holotipo de Proterotherium simplicidens Rovereto, 1914), porción anterior de la mandíbula con p2-m1 derechos y p1-p2 (incompleto) derechos; PVL 3196, dos restos mandibulares con dp4-m1 izquierdos y dp3-dp4 derechos y un m1? derecho incompleto.

\section{Neobrachytherium ullumense}

PVSJ 120, cráneo deformado con P3-M3 izquierdos y P2-M3 derechos; PVSJ 135, porción de rama mandibular derecha con p4 y m3 izquierdos; PVSJ 231, porción de rama mandibular derecha con m3 desgastado; MCNAM-PV 3222, fragmento maxilar izquierdo con P4 incompleto y M1-M3; MCNAM-PV 3223, fragmento mandibular izquierdo con $\mathrm{m} 2-\mathrm{m} 3$.

\section{Neobrachytherium sp.}

CRILAR PV 429, P3-M1 derechos y P3 izquierdo.

\section{Proterotherium cervioides}

MLP 69-XII-2-9 (holotipo), fragmento de maxilar izquierdo con P4-M2 y M3 en erupción; MACN PV 2631, dp4? izquierdo; MACN PV 4204, astrágalo izquierdo.

\section{Diadiaphorus eversus}

MACN A-5866 (holotipo), fragmento de molar superior izquierdo; MACN PV 13478, fragmento de premaxilar con parte de incisivo superior. 
Apéndice 2. Salidas de los cuatro análisis discriminantes realizados con InfoStat utilizando como variables la longitud y la anchura de piezas inferiores (p3-m3) de Brachytherium cuspidatum.

Appendix 2. Outputs of the four discriminant analysis perfomed with InfoStat using as variables the length and width of lower teeth (p3-m3) of Brachytherium cuspidatum.

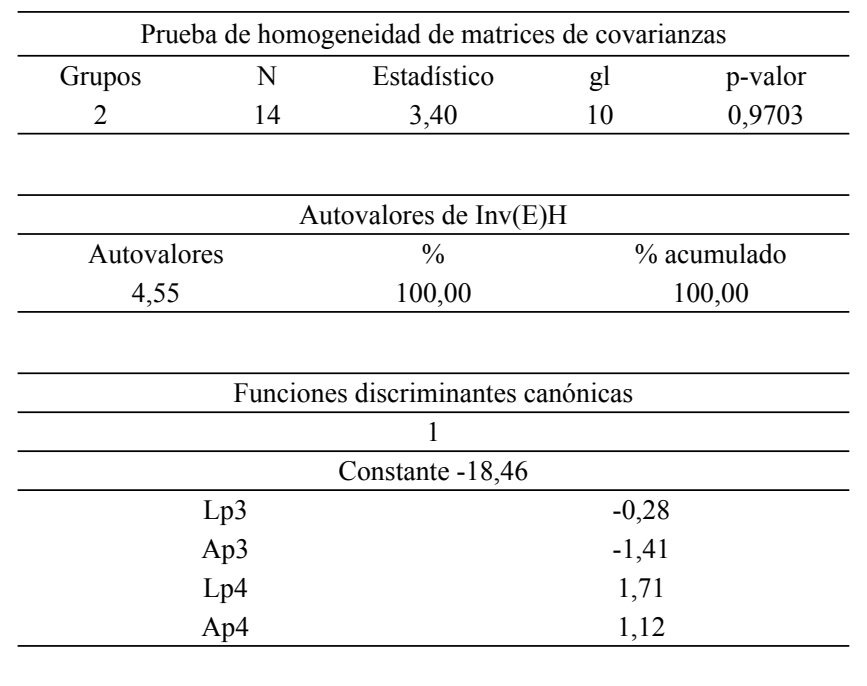

\begin{tabular}{|c|c|c|c|c|}
\hline \multicolumn{5}{|c|}{$\begin{array}{c}\text { Funciones discriminantes } \\
\text { - datos estandarizados con las varianzas comunes }\end{array}$} \\
\hline \multicolumn{5}{|c|}{1} \\
\hline Lp3 & & & $-0,34$ & \\
\hline Ap3 & & & $-1,20$ & \\
\hline Lp4 & & & 1,20 & \\
\hline Ap4 & & & 1,30 & \\
\hline \multicolumn{5}{|c|}{ Centroides en el espacio discriminante } \\
\hline Grupo & & & Eje 1 & \\
\hline B. cuspidatum & & & 1,71 & \\
\hline B. cuspidatum & & & $-2,28$ & \\
\hline \multicolumn{5}{|c|}{ Tabla de clasificación cruzada } \\
\hline Grupo & $\begin{array}{r}\text { B. cusp } \\
\text { mayor }\end{array}$ & $\begin{array}{l}\text { B. cusp } \\
\text { menor }\end{array}$ & Total & Error $(\%)$ \\
\hline B. cuspidatum mayor & 8 & 0 & 8 & 0,00 \\
\hline B. cuspidatum menor & 0 & 6 & 6 & 0,00 \\
\hline Total & 8 & 6 & 14 & 0,00 \\
\hline
\end{tabular}

\begin{tabular}{ccccc}
\hline \multicolumn{5}{c}{ Prueba de homogeneidad de matrices de covarianzas } \\
\hline Grupos & $\mathrm{N}$ & Estadístico & $\mathrm{gl}$ & $\mathrm{p}$-valor \\
\hline 2 & 15 & $-10,08$ & 10 & $>0,9999$ \\
\hline \multicolumn{5}{c}{ Autovalores de Inv(E)H } \\
\hline Autovalores & $\%$ & $\%$ acumulado \\
\hline 7,63 & 100,00 & 100,00 \\
\hline
\end{tabular}

\begin{tabular}{cc}
\hline \multicolumn{2}{c}{ Funciones discriminantes canónicas } \\
\hline 1 & \\
\hline Constante & $-25,85$ \\
\hline Lp4 & 1,53 \\
Ap4 & 0,55 \\
Lm1 & 0,40 \\
Am1 & $-0,71$ \\
\hline
\end{tabular}


Apéndice 2. Continuación.

Appendix 2. Continuation.

\begin{tabular}{|c|c|c|c|c|}
\hline \multicolumn{5}{|c|}{$\begin{array}{c}\text { Funciones discriminantes } \\
\text { - datos estandarizados con las varianzas comunes } \\
\end{array}$} \\
\hline \multicolumn{5}{|c|}{1} \\
\hline \multicolumn{2}{|c|}{ Lp4 } & & \multicolumn{2}{|c|}{0,82} \\
\hline \multicolumn{2}{|c|}{ Ap4 } & & \multicolumn{2}{|c|}{0,60} \\
\hline \multicolumn{2}{|c|}{ Lm1 } & & \multicolumn{2}{|c|}{0,26} \\
\hline \multicolumn{2}{|c|}{ Am1 } & & \multicolumn{2}{|c|}{$-0,70$} \\
\hline \multicolumn{5}{|c|}{ Centroides en el espacio discriminante } \\
\hline \multicolumn{2}{|c|}{ Grupo } & & \multicolumn{2}{|c|}{ Eje 1} \\
\hline \multirow{2}{*}{\multicolumn{2}{|c|}{$\begin{array}{l}\text { B. cuspidatum mayor } \\
\text { B. cuspidatum menor }\end{array}$}} & & \multicolumn{2}{|c|}{2,10} \\
\hline & & & \multicolumn{2}{|c|}{$-3,15$} \\
\hline \multicolumn{5}{|c|}{ Tabla de clasificación cruzada } \\
\hline Grupo & $\begin{array}{l}\text { B. cusp } \\
\text { mayor }\end{array}$ & $\begin{array}{l}\text { B. cusp } \\
\text { menor }\end{array}$ & Total & Error $(\%)$ \\
\hline $\begin{array}{l}\text { B. cuspidatum } \\
\text { mayor }\end{array}$ & 9 & 0 & 9 & 0,00 \\
\hline $\begin{array}{l}\text { B. cuspidatum } \\
\text { menor }\end{array}$ & 0 & 6 & 6 & 0,00 \\
\hline Total & 9 & 6 & 15 & 0,00 \\
\hline
\end{tabular}

\begin{tabular}{ccccc}
\hline \multicolumn{5}{c}{ Prueba de homogeneidad de matrices de covarianzas } \\
\hline Grupos & $\mathrm{N}$ & Estadístico & $\mathrm{gl}$ & p-valor \\
\hline 2 & 13 & $-9,10$ & 10 & $>0,9999$ \\
\hline
\end{tabular}

\begin{tabular}{ccc}
\hline \multicolumn{3}{c}{ Autovalores de $\operatorname{Inv}(\mathrm{E}) \mathrm{H}$} \\
\hline Autovalores & $\%$ acumulado \\
\hline $3,64100,00$ & & 100,00 \\
\hline
\end{tabular}

\begin{tabular}{cc}
\hline \multicolumn{2}{c}{ Funciones discriminantes canónicas } \\
\hline \multicolumn{2}{c}{1} \\
\hline Constante $-25,73$ & 0,93 \\
Lm1 & 0,69 \\
Am1 & 0,76 \\
Lm2 & $-0,52$ \\
Am2
\end{tabular}

Funciones discriminantes

- datos estandarizados con las varianzas comunes

\begin{tabular}{cc} 
- datos estandarizados con las varianzas comunes \\
\hline & 1 \\
\hline Lm1 & 0,56 \\
Am1 & 0,62 \\
Lm2 & 0,62 \\
Am2 & $-0,51$ \\
\hline
\end{tabular}

\begin{tabular}{cc}
\hline \multicolumn{2}{c}{ Centroides en el espacio discriminante } \\
\hline Grupo & Eje 1 \\
\hline B. cuspidatum mayor & 1,39 \\
B. cuspidatum menor & $-2,22$
\end{tabular}


Apéndice 2. Continuación.

Appendix 2. Continuation.

\begin{tabular}{ccccc}
\hline \multicolumn{5}{c}{ Tabla de clasificación cruzada } \\
\hline Grupo & B. cusp mayor & B. cusp menor & Total & Error(\%) \\
\hline B. cuspidatum mayor & 8 & 0 & 8 & 0,00 \\
B. cuspidatum menor & 0 & 5 & 5 & 0,00 \\
Total & 8 & 5 & 13 & 0,00 \\
\hline
\end{tabular}

\begin{tabular}{ccccc}
\hline \multicolumn{5}{c}{ Prueba de homogeneidad de matrices de covarianzas } \\
\hline Grupos & $\mathrm{N}$ & Estadístico & $\mathrm{gl}$ & $\mathrm{p}$-valor \\
2 & 12 & $-2,66$ & 10 & $>0,9999$ \\
\hline
\end{tabular}

\begin{tabular}{ccc}
\hline & Autovalores de $\operatorname{Inv}(\mathrm{E}) \mathrm{H}$ & \\
\hline Autovalores & $\%$ & $\%$ acumulado \\
\hline 2,15 & 100,00 & 100,00 \\
\hline
\end{tabular}

\begin{tabular}{cc}
\hline \multicolumn{2}{c}{ Funciones discriminantes canónicas } \\
\hline & \\
\hline Constante & $-21,67$ \\
\hline Lm2 & 1,53 \\
Am2 & $-0,27$ \\
Lm3 & 0,49 \\
Am3 & $-0,51$ \\
\hline
\end{tabular}

\begin{tabular}{cc}
\hline $\begin{array}{c}\text { Funciones discriminantes - datos estandarizados con las varianzas } \\
\text { comunes }\end{array}$ \\
\hline \multicolumn{2}{c}{1} \\
\hline Lm2 & 1,20 \\
Am2 & $-0,38$ \\
Lm3 & 0,57 \\
Am3 & $-0,55$ \\
\hline
\end{tabular}

\begin{tabular}{cc}
\hline \multicolumn{2}{c}{ Centroides en el espacio discriminante } \\
\hline Grupo & Eje 1 \\
\hline B. cuspidatum mayor & 0,95 \\
B. cuspidatum menor & $-1,89$ \\
\hline
\end{tabular}

\begin{tabular}{ccccc}
\hline \multicolumn{5}{c}{ Tabla de clasificación cruzada } \\
\hline Grupo & B. cusp mayor & B. cusp menor & Total & Error(\%) \\
\hline B. cuspidatum mayor & 8 & 0 & 8 & 0,00 \\
B. cuspidatum menor & 0 & 4 & 4 & 0,00 \\
Total & 8 & 4 & 12 & 0,00 \\
\hline
\end{tabular}


Apéndice 3. Listado de caracteres y sus estados utilizados en el análisis filogenético de los Proterotheriidae. $\mathrm{N}$ indica un carácter nuevo respecto a Villafañe et al. (2012).

Appendix 3. List of characters and characters states used in the phylogenetic analysis of the Proterotheriidae. $\mathrm{N}$ indicates new character according to Villafañe et al. (2012).

0. Hipsodoncia: (0) braquiodonte; (1) mesodonte; (2) protohipsodonte.

1. Pliegues labiales del paracono y metacono: (0) desarrollados; (1) poco desarrollados; (2) ausentes.

2. Cíngulos labiales en los molares superiores: (0) ausentes; (1) presentes.

3. Desarrollo de los estilos: (0) pequeños; (1) moderados; (2) desarrollados.

4. Desarrollo relativo de los estilos en M1-M3: (0) igualmente desarrollados; (1) mesostilo más desarrollado; (2) parastilo más desarrollado.

5. Unión del protocono al hipocono en M1-M2: (0) muy unidos sin dejar un sulcus muy marcado; (1) con tendencia a separarse dejando un sulcus marcado; (2) separados, dejando un sulcus profundo.

6. Precíngulo en M1-M3: (0) sin unión al protocono; (1) unido al protocono; (2) alcanzando el surco lingual posterior.

7. Metacónulo en P3: (0) presente; (1) ausente.

8. Metacónulo en P4: (0) unido al protocono; (1) unido al hipocono; (2) cercano al metacono; (3) aislado.

9. Metacónulo en M1-M2: (0) unido al protocono; (1) unido al hipocono; (2) unido a la pared entre el hipocono y el protocono; (3) unido al metacono; (4) aislado.

10. Desarrollo del metacónulo en M1-M2: (0) poco desarrollado; (1) desarrollado.

11. Metacónulo en M3: (0) presente; (1) ausente.

12. Hipocono en P3: (0) ausente; (1) presente.

13. Hipocono en P4: (0) ausente; (1) presente.

14. Desarrollo del hipocono en P4: (0) débil; (1) desarrollado.

15. Hipocono en M3: (0) ausente; (1) presente.

16. Protocono en P2: (0) ausente; (1) presente.

17. Lóbulo distal en m3: (0) presente; (1) ausente.

18. Entocónido en m1-m2: (0) mayor que el hipoconúlido; (1) igual o menor que el hipoconúlido; (2) ausente.

19. Paracónido en m1-m2: (0) ausente; (1) vestigial unido al paralófido; (2) desarrollado, con tendencia a unirse al metacónido.

20. Paralófido en m1-m2: (0) desarrollado, terminado lingualmente; (1) menos desarrollado, terminado en posición medial anterior.

21. Entocónido en m3 (N): (0) libre; (1) unido al hipoconúlido; (2) ausente. 
Apéndice 4. Matriz de caracteres utilizada en el análisis filogenético de los Proterotheriidae. Las letras representan estados polimórficos: A, 0,$1 ; \mathbf{B}, 0,3 ; \mathbf{C}, 1,2 ; \mathbf{D}, 2,3$.

Appendix 4. Character-taxon matrix used in the phylogenetic analysis of the Proterotheriidae. Letters indicate polymorphic codings: A, 0,$1 ; \mathbf{B}, 0,3 ; \mathbf{C}, 1,2 ; \mathbf{D}, 2,3$.

\begin{tabular}{|c|c|c|c|c|c|c|c|c|c|c|c|c|c|c|c|c|c|c|c|c|c|c|}
\hline Taxon & $\mathbf{0}$ & 1 & 2 & 3 & 4 & 5 & 6 & 7 & 8 & 9 & 10 & 11 & 12 & 13 & 14 & 15 & 16 & 17 & 18 & 19 & 20 & 21 \\
\hline Paranisolambda prodromus & 0 & 0 & 1 & 1 & 0 & 2 & 1 & - & - & 1 & 1 & 0 & - & - & - & 0 & 1 & 1 & 0 & 2 & 0 & 0 \\
\hline Paramacrauchenia scamnata & 0 & 0 & 0 & 1 & 0 & 0 & 0 & 0 & $?$ & 2 & 0 & A & 0 & 0 & - & 0 & 0 & 0 & 1 & 0 & 1 & 1 \\
\hline Prolicaphrium specillatum & 0 & 1 & 1 & 1 & 1 & 2 & 1 & 0 & 3 & 4 & 1 & 0 & 0 & 1 & 0 & 0 & 1 & 0 & 1 & 0 & 1 & 1 \\
\hline Lambdaconus lacerum & 0 & 0 & 0 & 0 & 0 & 0 & 1 & 0 & 0 & 2 & $\mathrm{~A}$ & 0 & 0 & 0 & - & 0 & 0 & 0 & 0 & 0 & 1 & 1 \\
\hline Picturotherium migueli & 0 & 0 & 1 & 1 & 0 & 0 & 1 & 0 & 0 & 2 & 1 & 0 & 1 & 1 & 0 & 0 & 1 & 0 & 1 & 0 & 1 & 1 \\
\hline Tetramerorhinus lucarius & 0 & 2 & 1 & 1 & 0 & 2 & 1 & 0 & 3 & 4 & 1 & 0 & 1 & 1 & 1 & 1 & 1 & 0 & 1 & 1 & 0 & 1 \\
\hline Diadiaphorus majusculus & 1 & 2 & 1 & 2 & 2 & 2 & 2 & 1 & $\mathrm{D}$ & 3 & 1 & 0 & 1 & 1 & 1 & 0 & 1 & 1 & 1 & 0 & 0 & 2 \\
\hline Thoatherium minusculum & 1 & $\mathrm{C}$ & 1 & 1 & 2 & 1 & 0 & 1 & $\mathrm{~B}$ & 0 & 0 & $\mathrm{~A}$ & 1 & 1 & 1 & A & 1 & 1 & 2 & A & 0 & 2 \\
\hline Anisolophus floweri & 0 & 1 & 1 & 1 & $\mathrm{C}$ & 1 & 1 & $?$ & 3 & 4 & 1 & 0 & $?$ & 1 & 0 & 0 & $?$ & 0 & 0 & 0 & 0 & 1 \\
\hline Anisolophus minusculus & 0 & 1 & 1 & 1 & 1 & 1 & 1 & 0 & $?$ & 4 & 1 & $?$ & 1 & $?$ & $?$ & $?$ & $?$ & 0 & 0 & 0 & 0 & 1 \\
\hline Thoatheriopsis mendocensis & 1 & 2 & 1 & 2 & 2 & 2 & 1 & 0 & 0 & 0 & 1 & 0 & 1 & 1 & 1 & 1 & 1 & $?$ & $?$ & $?$ & $?$ & $?$ \\
\hline Proterotherium cervioides & 0 & 0 & 0 & 1 & 0 & 2 & 0 & $?$ & 0 & 0 & 1 & 0 & $?$ & 1 & 0 & $?$ & $?$ & $?$ & $?$ & $?$ & $?$ & $?$ \\
\hline Brachytherium cuspidatum & 1 & 1 & 1 & 1 & 2 & 2 & 0 & 0 & 0 & 4 & 1 & 0 & 1 & 1 & 1 & 0 & 1 & 0 & 1 & 1 & 0 & 1 \\
\hline Epitherium laternarium & 2 & 2 & 1 & 1 & 2 & 2 & A & 0 & $?$ & 1 & 0 & 0 & $?$ & 1 & $?$ & 1 & 1 & 0 & $?$ & 1 & 0 & 1 \\
\hline Eoauchenia primitiva & 2 & 2 & 1 & 1 & 2 & $?$ & $?$ & $?$ & $?$ & $?$ & $?$ & $?$ & $?$ & $?$ & $?$ & $?$ & $?$ & $?$ & $?$ & $?$ & $?$ & $?$ \\
\hline Neobrachytherium ullumense & 1 & 1 & 1 & 2 & 1 & 1 & 0 & 0 & $?$ & 2 & 0 & 1 & $?$ & 1 & 1 & 1 & 1 & 1 & 1 & 1 & 0 & 0 \\
\hline Neobrachytherium morenoi & 1 & 1 & 1 & 2 & 2 & 2 & 0 & 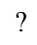 & 1 & 1 & 0 & $?$ & $?$ & 1 & 1 & $?$ & $?$ & $?$ & 1 & 2 & 0 & $?$ \\
\hline Neobrachytherium ameghinoi & 1 & 2 & 1 & 2 & 2 & 1 & 0 & $?$ & $?$ & 2 & 0 & 0 & $?$ & $?$ & $?$ & 1 & $?$ & 1 & 1 & 1 & 0 & 0 \\
\hline Neobrachytherium intermedium & 1 & 1 & 1 & 2 & 2 & 2 & 0 & 0 & A & 1 & 0 & 0 & 1 & 1 & 1 & 1 & 1 & 1 & 1 & 1 & 0 & 1 \\
\hline Diadiaphorus eversus & 2 & $?$ & $?$ & $?$ & $?$ & 2 & 2 & $?$ & $?$ & $?$ & 1 & $?$ & $?$ & $?$ & $?$ & $?$ & $?$ & $?$ & $?$ & $?$ & $?$ & $?$ \\
\hline
\end{tabular}

